\title{
In-situ Chemical Dynamics and Phase Mapping under Steep Thermal Gradients using Time-Resolved and Spatially Resolved X-Ray Diffraction
}

\author{
J. Wong, E.M. Larson, J.B. Holt, T. Ressler, J.W. Elmer
}

This article was submitted to International Alloys Conference-2, Davos, Switzerland, August 8-13, 1999

\section{September 17, 1999}

Lawrence

Livermore

National

Laboratory 


\section{DISCLAIMER}

This document was prepared as an account of work sponsored by an agency of the United States Government. Neither the United States Government nor the University of California nor any of their employees, makes any warranty, express or implied, or assumes any legal liability or responsibility for the accuracy, completeness, or usefulness of any information, apparatus, product, or process disclosed, or represents that its use would not infringe privately owned rights. Reference herein to any specific commercial product, process, or service by trade name, trademark, manufacturer, or otherwise, does not necessarily constitute or imply its endorsement, recommendation, or favoring by the United States Government or the University of California. The views and opinions of authors expressed herein do not necessarily state or reflect those of the United States Government or the University of California, and shall not be used for advertising or product endorsement purposes.

This is a preprint of a paper intended for publication in a journal or proceedings. Since changes may be made before publication, this preprint is made available with the understanding that it will not be cited or reproduced without the permission of the author.

This report has been reproduced

directly from the best available copy.

Available to DOE and DOE contractors from the

Office of Scientific and Technical Information

P.O. Box 62, Oak Ridge, TN 37831

Prices available from (423) 576-8401

http://apollo.osti.gov/bridge/

Available to the public from the

National Technical Information Service

U.S. Department of Commerce

5285 Port Royal Rd.,

Springfield, VA 22161

http://www.ntis.gov/

OR

Lawrence Livermore National Laboratory

Technical Information Department's Digital Library

http://www.llnl.gov/tid/Library.html 


\title{
In-situ Chemical Dynamics and Phase Mapping under Steep Thermal Gradients using Time-Resolved and Spatially Resolved X-Ray Diffraction
}

\author{
Joe Wong, E.M. Larson ${ }^{(a)}$, J.B. Holt ${ }^{(b)}$, T. Ressler ${ }^{(\mathrm{c})}$ and J. W. Elmer \\ Lawrence Livermore National Laboratory, University of California, \\ P.O. Box 808, Livermore, California 94551, USA
}

\begin{abstract}
Time-resolved and spatially-resolved diffraction techniques have been developed recently to perform materials dynamics study in-situ extending into the time and spatial domain in high temperature processes. The applications of these methods to investigate the chemical dynamics of solid combustion reactions and to map phases and their transformation in fusion welds are exemplified in this paper.
\end{abstract}

\section{Introduction}

Real-time studies of dynamical processes in-situ under severe temperature or pressure conditions often pose a challenge for experimentalists. In materials synthesis such as combustion synthesis and materials joining processes such as welding, high intensity heat sources are used to create steep thermal gradients that rapidly heat and cool materials to and from their melting point. This rapid thermal cycling induces solid state reactions and/or phase transformations both on heating and on cooling, and causes melting and solidification in regions of the material where the liquidus temperature has been exceeded. Composition and/or structure fluctuations are expected to occur along thermal gradients, and microstructural discontinuities exist at (or near) the location of each phase transformation isotherm.

Combustion synthesis is a relatively novel mode of preparing high temperature materials via solid-state reactions. These reactions are universally accompanied by the release of a large amount of heat. Once ignited with an external heat source, these solid combustion synthesis (SCS) reactions become self-sustained and propagate to completion within seconds. Also known as self-propagating 
high temperature synthesis (SHS) reactions, these processes are characterized by a fast-moving combustion front ( 1 to $100 \mathrm{~mm} / \mathrm{s}$ ) and a self-generated temperature varying from 1000 to $4000 \mathrm{~K}$. A number of ceramic, intermetallic and composite materials have been synthesized by this method ${ }^{1,2}$, including high temperature superconducting oxides 3,4 .

Although the basic concepts of this method of materials synthesis are relatively easy to apply in principle, there remains a number of basic questions concerning the physical and chemical nature as well as the dynamics of phase transformation within the moving combustion front. The situation is true even with the most simple $\mathrm{A}+\mathrm{B} \rightarrow \mathrm{AB}$ combustion reactions. Until recently ${ }^{5-7}$, it has been difficult to investigate these reactions because of the speed and extreme thermal conditions. Examinations of reactant and product phases and their microstructures are possible with x-ray diffraction and a variety of optical and electron microscopies. However, the high temperature and fast rates of combustion preclude any in-situ investigation of structural changes and chemical dynamics in the combustion zone in real time with most conventional techniques.

Material systems where thermally induced phase transformations play a significant role include allotropic elements such as pure titanium (hcp $\rightarrow$ bcc); two-phase alloys such as stainless steels ( $\mathrm{fcc} \rightarrow \mathrm{bcc}$ ); martensitic alloys such as iron-based steel alloys (fcc $\rightarrow \mathrm{bct}$ ); and dispersionstrengthened alloys. Most of the phase transformations of interest will involve deviations from equilibrium microstructures, resulting in partial transformations and/or the creation of metastable phases. These types of phase transformations have aroused a lot of interest in recent years in welding research development and in the metallurgical community ${ }^{8}$.

From a practical standpoint, solid state phase transformations and their kinetics play an important role in understanding various problems associated with thermal processing of materials such as sub-solidus cracking, cold cracking and distortion caused by residual stresses ${ }^{9,10}$. Solution to these problems will greatly be facilitated by the development of novel experimental methods for determining phase transformation behavior in the steep thermal gradients and at the high cooling rates. Until more recently ${ }^{11,12}$ no direct method exists for investigating solid state phase transformations that take place. Conventional methods for studying general phase transformation 
behavior are most indirect and of a post-mortem nature. Moreover, these methods only provide data for low heating and cooling rates on the order of $\sim 1 \mathrm{~K} / \mathrm{s}$, which is much less than those of arc welds $\left(10-10^{3} \mathrm{~K} / \mathrm{s}\right)$, and laser and electron beam welds $\left(10^{2}-10^{4} \mathrm{~K} / \mathrm{s}\right)$.

In this paper, we describe a couple of recently developed synchrotron techniques and their applications (a) to follow the course of reaction of a carefully chosen $\mathrm{Ta}+\mathrm{C} \rightarrow \mathrm{TaC}$ solid combustion system with a time resolution of $50 \mathrm{~ms}$ by recording the time-resolved x-ray diffraction (TRXRD) patterns in situ and at high temperature and (b) to probe the phases and map their locations in steep thermal gradients down to $200 \mu \mathrm{m}$ in spatial extent in a Ti fusion weld by recording the spatially-resolved x-ray diffraction (SRXRD) patterns in situ, in real time and at temperature during the welding process.

The choice of the Ta-C combustion system is two-fold. Firstly, the combustion synthesis of both $\mathrm{TaC}$ and $\mathrm{Ta}_{2} \mathrm{C}$ from $\mathrm{Ta}$ and $\mathrm{C}$ is atypical of many other combustion reactions because the adiabatic temperatures $\left(2438{ }^{\circ} \mathrm{C}\right.$ and $2360{ }^{\circ} \mathrm{C}$ for $\mathrm{TaC}$ and $\mathrm{Ta}_{2} \mathrm{C}$ respectively) are below the melting temperatures of tantalum, carbon, the carbides and known eutectic compositions ${ }^{13}$. Therefore, these combustion reactions must occur in the solid state with no participation of a liquid phase. In fact, it has been suggested that the rate controlling step in the combustion reactions of $\mathrm{Ta}$ and $\mathrm{C}$ is the diffusion of carbon into the tantalum particles ${ }^{14-16}$. Secondly, Ta and its compounds are strong xray scatterers which in turn enable short scan time of each diffraction pattern down to tens of milliseconds with good signal-to-noise ratios ${ }^{17}$.

To illustrate novelty of the SRXRD technique, we choose titanium fusion welds as a case study ${ }^{18}$, and apply this technique to map completely the phases and their solid-state transformations in the HAZ in-situ during the welding process. In a fusion weld, two distinct microstructural regions are formed: (i) the fusion zone, FZ, in which melting, solidification and solid state phase transformation have taken place, and (ii) the heat affected zone, HAZ, in which only solid state phase transformations have taken place. In each zone, metastable microstructures may be created that can enhance or degrade the quality of the weld, depending on the materials and 
processing parameters. Results of profile analysis of the diffraction data were used to elucidate the evolution of various types of high temperature microcstructures in the vicinity of the HAZ surrounding the liquid weld pool. The observed phase boundaries are compared with those calculated from a heat flow model ${ }^{19}$.

\section{Experimental Methods}

\subsection{Time-resolved diffraction measurements}

The diffraction-reaction chamber, and detectors are shown schematically in Fig. 1. A detailed description of the apparatus has been given elsewhere 6,20 . This apparatus was designed to accept a synchrotron beam incident at an angle of $\sim 20^{\circ}$ on a combustion specimen. The detectors are silicon position-sensitive photodiode arrays manufactured by Princeton Instruments, NJ. Each array is 25 mm long containing 1024 pixels, and is capable of recording a full scan of 1024 pixels in 4 ms. Diffraction experiments were performed at Brookhaven National Synchrotron Light Source (NSLS) on beamline X-11A using a focussed beam monochromatized with a double $\operatorname{Si}(111)$ crystal at $8048.0 \mathrm{eV}(\lambda=1.5406 \AA)$. The detectors each spanning $6^{\circ} 2 \theta$ were centered at $36.5^{\circ}$ and $72^{\circ}$ (where $\theta$ is the Bragg angle for a given reflection) to collect the Ta (110) and (211) diffraction peaks at the start of the reaction as well the major diffraction peaks of both $\mathrm{TaC}$ and $\mathrm{Ta}_{2} \mathrm{C}$ products in these $2 \theta$ windows. The vertical hutch slit was adjusted to a height of $0.46 \mathrm{~mm}$ for the $\mathrm{Ta}+\mathrm{C}$ reaction (I) and $0.25 \mathrm{~mm}$ for the faster $2 \mathrm{Ta}+\mathrm{C}$ reaction (II). These in turn produced an $\mathrm{x}$-ray beam of $1.1 \mathrm{~mm}$ and $0.6 \mathrm{~mm}$ long respectively along the length of the sample at a $\theta$ angle of $25^{\circ}$.

Diffraction patterns were collected and stored at constant time intervals from the initiation of the reaction through completion with a total collection time ranging from 15 to 50 seconds. A typical TRXRD experiment might consist of 500 scans each collected at $100 \mathrm{~ms}$. Scan times of both 50 and $100 \mathrm{~ms}$ time frames were used for both reactions I and II. Data sets were collected during the burns of several samples of each mixture. Some expansion of the material was expected and took place during the reaction causing slight shifts in the peak positions to high $2 \theta$ value. Prior to ignition, the 
room temperature diffraction pattern of each specimen was routinely recorded to optimize sample position, choice of $2 \theta$-window and $\mathrm{S} / \mathrm{N}$ ratios with scan time. Diffraction scans were also taken of the cooled product 5-10 minutes after completion of the reaction. Conventional powder diffraction patterns from the surface as well as the interior of each reacted samples were later collected in the laboratory to verify the product phase using a conventional x-ray tube

\subsection{Preparation of combustion synthesis specimens}

Stoichiometric mixtures of metal and carbon powders (1:1 and 2:1) respectively for reaction I: $\mathrm{Ta}+\mathrm{C}=\mathrm{TaC}$ and reaction II: $2 \mathrm{Ta}+\mathrm{C}=\mathrm{Ta}_{2} \mathrm{C}$ were weighed and mechanically mixed in a SPEX mixer for 10-30 min. The combustion specimens were pressed cylindrical pellets, $19 \mathrm{~mm}$ in diameter and about $25 \mathrm{~mm}$ long with a green density of $\sim 55 \%$. The pressed samples were ignited at one end by a resistively heated tungsten coil. After ignition, the burn became self-sustaining due to exothermicity of the reaction. All $\mathrm{Ta}+\mathrm{C}$ and $2 \mathrm{Ta}+\mathrm{C}$ reactions reported here were performed in helium at a pressure of $1 \mathrm{~atm}$ or slightly less to obviate oxidation and to minimize air attenuation of the diffracted signals.

\subsection{Spatially resolved $x$-ray diffraction (SRXRD) measurements}

SRXRD experiments were performed on the 31-pole-wiggler beam line $10-2^{21}$ at Stanford Synchrotron Radiation Laboratory (SSRL) with the storage ring operating at an energy of $3.0 \mathrm{GeV}$ and injection current of $\sim 100 \mathrm{~mA}$. Details of the SRXRD instrument can be found elsewhere ${ }^{11.12}$. A schematic representation of the experimental set-up is shown in Fig. 2.

XRD measurements were made using a monochromatic x-ray beam with a photon energy of $8.5 \mathrm{keV}$ (wavelength $\lambda=1.4586 \AA$ ). A Si(111) double crystal monochromator was used preceded by a toroidal mirror in a 1:1 focusing geometry. The spatial resolution of the experiment was determined by a $180 \mu \mathrm{m}$ pinhole placed $30 \mathrm{~cm}$ in front of the weld. A photon flux of about $2 \cdot 10^{9}$ 
photons per second was determined using an ionization chamber situated between pinhole and weld. From photographic paper measurements the beam size on the titanium bar was estimated to be $\sim 200 \mu \mathrm{m}$. X-ray diffraction patterns from the titanium bar were recorded on a water-cooled 5 cm long 2048 elements position sensitive photodiode array detector. The detector, similar to those described in the TRXRD experiments, but upgraded to $50 \mathrm{~mm}$ long to contain 2048 pixels, was placed $9.5 \mathrm{~cm}$ from the weld at an angle of $30^{\circ}$ with respect to the primary synchrotron beam covering a $2 \theta$ range from $30^{\circ}$ to $60^{\circ}$. The detector and associated ST121 data acquisition system were manufactured by Princeton Instruments ${ }^{22}$. The latter was used to store and display the $\mathrm{x}$-ray diffraction data in real time.

SRXRD patterns were measured during welding by positioning the beam at a predetermined location with respect to the welding electrode. A single diffraction pattern at each location was collected for $6 \mathrm{~s}$ while the bar rotated under the torch at a constant speed of $0.2 \mathrm{rpm}$. By incrementally jogging the weld to new locations in $200 \mu \mathrm{m}$ intervals, a series of spatiallyresolved x-ray diffraction patterns was collected along a lineal scan direction perpendicular to and away from the centerline of the weld. For example, a typical run consisted of gathering $40 \mathrm{x}$-ray diffraction patterns spanning a range of $8 \mathrm{~mm}$ through the HAZ. A schematic representation of the mapping procedure is presented in Fig. 3. The dimension of the liquid weld pool was determined from the experiment, whereas the dimension of the heat affected zone was estimated from a heatflow model ${ }^{19}$. Each dotted line represents a single experimental SRXRD run, and each dot denotes an x-ray diffraction pattern collected at this location with respect to the center of the weld. After completing a run, the weld was allowed to cool to room temperature and the electrode was repositioned to a new starting location with respect to the x-ray beam prior to taking the next 
series of data. As can be seen from Fig. 3, by symmetry only one half the weld was mapped experimentally. In the following analysis, only the top half of the entire weld will be displayed for simplicity.

\subsection{Titanium samples for welding}

Cylindrical welding samples were machined from as received grade 2 commercially pure titanium measuring $10.2 \mathrm{~cm}$ in diameter and $12.7 \mathrm{~cm}$ length. These samples had a surface finish of 1.6 $\mu \mathrm{m}$ RMS and were round to within $10 \mu \mathrm{m}$ on the diameter. Chemical analysis was performed using combustion analysis for $\mathrm{O}, \mathrm{C}, \mathrm{N}$, and $\mathrm{H}$, and inductively coupled plasma analysis for the remaining elements. The results show the following impurity content (wt \%): $0.14 \% \mathrm{Fe}, 0.17 \%$ O, $0.03 \%$ Al, $0.02 \%$ Cr, 0.008\% C, $0.001 \% \mathrm{H}, 0.014 \% \mathrm{~N}, 0.02 \% \mathrm{Ni}, 0.005 \% \mathrm{~V}, 0.004 \% \mathrm{Si}$. The final cylindrical samples were then vacuum annealed for $30 \mathrm{~min}$ at $400{ }^{0} \mathrm{C}$ to partially recover the cold work that was introduced during machining.

\subsection{Welding setup and procedure}

Gas tungsten arc welds were made on the titanium bars using a 150 A direct current welding power supply with the electrode held at negative polarity. A new welding electrode made of W-2 $\% \mathrm{Th}, 4.7 \mathrm{~mm}$ in diameter, was used for each weld. The power was maintained constant at $1.9 \mathrm{~kW}$ (100 A, $19 \pm 0.5 \mathrm{~V})$ for all welds, and helium was used as both a welding and shielding gas. The titanium bar was rotated at a constant speed of $0.20 \mathrm{rpm}$ below the fixed electrode, which corresponds to a surface welding speed of $1.1 \mathrm{~mm} / \mathrm{s}$, and resulted in an 11 to $12 \mathrm{~mm}$ wide fusion zone on the surface of the titanium bar. All welding was performed inside a chamber purged with ultra high purity helium (99.999\%) to minimize oxidation of the titanium that had occurred ${ }^{12}$. The He gas was also passed through the torch during welding to further prevent oxidation in the weld 
region and to cool the torch. The welding assembly was integrally mounted to a translation stage driven by a stepper motor with $10 \mu \mathrm{m}$ precision. Spatial mapping of the phases in the various regions of the HAZ was performed by using the translation stage to manipulate the weld (welding torch and workpiece) with respect to the fixed x-ray beam in order to sample discrete regions around the weld. Movements perpendicular to the centerline of the weld were controlled by a computer and were performed by direct translation of the workpiece with respect to the x-ray beam. An in-house designed software package was developed on a personal computer using LabView software v4.0 to control the position of the weld with respect to the $\mathrm{x}$-ray beam, to control the bar rotational speed (welding speed), and to trigger the data acquisition system in a second computer.

\section{Results}

\subsection{Time-resolved diffraction data}

\subsubsection{The synthesis of TaC}

Fig. 4 shows a series of typical time-resolved diffraction patterns for the synthesis of $\mathrm{TaC}$ from a stoichiometric mixture of its constituent elements. In this TRXRD experiment, the detector counting time per diffraction pattern (scan) was $100 \mathrm{~ms}$, and 500 such scans were recorded to yield a total measurement time of $50 \mathrm{~s}$. In this $3-\mathrm{D}$ plot, only every 10 th scan was plotted to ease visual representation of the course of reaction with time. $t=0$ corresponds to triggering of the detector to initiate collection of diffraction patterns of the reactant mixture prior to arrival of combustion front at the area of the sample illuminated by the synchrotron beam.

Examination of such a time series of TRXRD diffraction scans shows that the sequence of chemical events in the combustion zone may be represented by a subset of selected scans as plotted in Fig. 4. Two tantalum metal peaks are prominent until $5.6 \mathrm{~s}$ have passed when the Debye-Waller effect diminishes their intensities due to arrival of the high temperature combustion front. The Ta (110) peak splits at $6.7 \mathrm{~s}$ and another peak is observed at $35^{\circ} 2 \theta$. The Ta (211) has almost disappeared and only a hint of scattering is observed in the center of the second detector at 
high angle. At $7.5 \mathrm{~s}$ both $\mathrm{TaC}$ and $\mathrm{Ta}_{2} \mathrm{C}$ peaks are clearly registered in both detectors. Considering the combustion front velocity $(\sim 2.0 \mathrm{~mm} / \mathrm{s})$ and beam width of $1.1 \mathrm{~mm}$ along the direction of combustion front, the combustion front would pass through the x-ray spot in $\sim 0.55$ s. After 30 seconds, most of the scattering from $\mathrm{Ta}_{2} \mathrm{C}$ has disappeared leaving only $\mathrm{TaC}$ peaks prominent in the patterns, which shifted to higher $2 \theta$ values indicative of lattice contraction upon cooling. Laboratory XRD patterns showed only trace amounts of subcarbide in the interior as well as on the surface of reacted samples.

\subsubsection{The Synthesis of $\mathrm{Ta}_{2} \mathrm{C}$}

The $2 \mathrm{Ta}+\mathrm{C} \rightarrow \mathrm{Ta}_{2} \mathrm{C}$ reaction was also monitored at both $100 \mathrm{~ms}$ and $50 \mathrm{~ms}$ time scale and the corresponding TRXRD scans are shown in Fig. 6. Only $50 \mathrm{~ms}$ ( one TRXRD frame) elapses from the time the Ta peaks begin to decrease at $\mathrm{t}=1.60 \mathrm{~s}$ and the major $\mathrm{Ta}_{2} \mathrm{C}$ peaks appear at $\mathrm{t}=1.65$ s. By the next frame, all the subcarbide peaks are evident with no indication of any other species present. Since this reaction was a faster and to test spatial resolution of the diffraction peaks, the hutch slit was adjusted to $0.25 \mathrm{~mm}$. At a velocity of $5 \mathrm{~mm} / \mathrm{s}$, the burn front would pass through the $0.6 \mathrm{~mm}$ long x-ray beam spot in $0.12 \mathrm{~s}$ or $120 \mathrm{~ms}$.. The same scenario is replayed in all of the TRXRD data recorded for this reaction. However, there is no indication of any intermediate carbide phase. In post diffraction scans, $\mathrm{Ta}_{2} \mathrm{C}$ is the only tantalum-containing phase present on the surface and in the interior of the combusted sample.

\subsection{Spatially resolved $x$-ray diffraction data: Phase mapping in the HAZ of Ti fusion welds}

Pure titanium exhibits two phase transitions: an $\alpha \rightarrow \beta$ phase transformation in the solid state at $882{ }^{\circ} \mathrm{C}$ and melting at $1668{ }^{\circ} \mathrm{C}{ }^{23}$. In commercially pure grade 2 titanium employed in this work, the allotropic transformation from a hep $\alpha$-phase to a bcc $\beta$-phase occurs at $\sim 915^{\circ} \mathrm{C}$ due to the presence of iron, oxygen, and other impurities ${ }^{23}$. During the welding process, these phase transitions give rise to two distinct microstructural regions: a fusion zone (FZ) in which melting upon heating 
and solidification on cooling occur and a heat-affected zone (HAZ), in which the $\alpha \rightarrow \beta$ solid-state phase transformation and other microstructural changes take place. A typical series of SRXRD patterns measured across the $\alpha \rightarrow \beta$ phase transformation isotherm is shown in Fig. 7. The starting position and scan direction of the SRXRD run with respect to the center of the weld are shown by the dotted arrow in the inset. A transition from a $\beta$-Ti bcc pattern at high temperature inside the HAZ, to a $\alpha+\beta$-mixed zone, and eventually back to the $\alpha$-Ti hcp pattern can be seen. In addition to phase transformations, the material undergoes annealing and recrystallization in the cooler region and outside of the HAZ. SRXRD data obtained from different starting positions with respect to the weld center may be classified into five principal diffraction patterns. These patterns are labeled as $\alpha$ for the base hcp metal, $\alpha_{\mathbf{A R}}$ for the annealed and partially re-crystallized hcp phase, $\alpha_{\mathbf{R G}}$ for the re-crystallized and grain growth in the hcp phase, $\beta$ for the fully transformed high temperature bcc phase and $\alpha_{\mathbf{B T}}$ for the back transformed hcp phase. Examples for each of the principal patterns are displayed in Fig. 8 together with one for the $\alpha+\beta$-coexistence region. It should be noted that all principal diffraction patterns belong to either the $\alpha$-Ti or the $\beta$-Ti phase, but indicate differences in texture, degree of re-crystallization or annealing, or phase concentration. These principal diffraction patterns and the associated microstructures are described in detail in the following section.

\section{Discussion}

\subsection{Chemical dynamics of the Ta-C combustion synthesis}

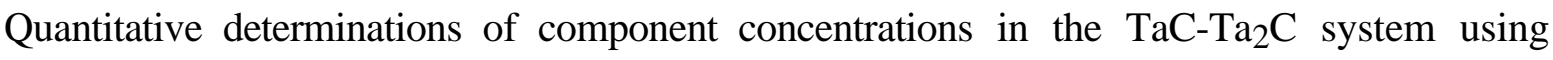
intensities of diffraction peaks have been reported ${ }^{24}$. In the present work the concentration of each of the Ta reactant, $\mathrm{Ta}_{2} \mathrm{C}$ and $\mathrm{TaC}$ final product at a given instant of time in the course of the reaction 
is directly proportional to the intensities of all observed diffraction lines for the respective phase as shown in the TRXRD patterns given in Figs. 4-6. The summation of intensity over all lines eliminates effects of preferred orientation in the "powder" patterns observed using the present diffraction geometry. The intensity sum for each phase is then normalized to its maximum value and plotted as a function of time to yield a set of normalized concentration profiles vs. time. These profiles are shown in Figs. 9 and 10 for reaction I and reaction II respectively.

Consider first the $\mathrm{Ta}+\mathrm{C}$ reaction. In Fig. 9, it is seen that the reduction in intensity of the Ta metal peak due to the Debye-Waller effect from pre-heating of the sample is responsible for the slope of the metal concentration between 2.0 - $5.5 \mathrm{~s}$. Note that the Ta concentration profile intersects first with that of the $\mathrm{Ta}_{2} \mathrm{C}$ intermediate, and that the $\mathrm{TaC}$ concentration has not reached its maximum until the $\mathrm{Ta}_{2} \mathrm{C}$ concentration has grown and then diminished. Also, the chemical reaction is not confined to a narrow zone at the combustion front but continues after the passage of the front. The reaction temperature remains above $1200{ }^{\circ} \mathrm{C}$ for approximately 4 seconds since the average combustion front velocity is $\sim 2 \mathrm{~mm} / \mathrm{s}^{17}$. The normalized intensity plot of Fig. 9 clearly shows that it takes 3-4 seconds for the growth of the TaC phase. This clearly substantiates the premise that the combustion synthesis reaction for TaC continues for several seconds and that an equilibrium is not reached until well after the passage of the burn front.

In solid state chemical reactions the interfacial area between reactants may influence the overall rate. If transport of atoms to the interface becomes too slow then the interfacial reaction becomes rate controlling. With most combustion reactions for metal carbides syntheses the melting point of the metal reactant is low enough that it melts at the combustion front and by capillary action surrounds the carbon particles. The occurrence maximizes the interfacial area. Furthermore, it seems unlikely that at $1700{ }^{\circ} \mathrm{C}$ the vapor pressure of $\mathrm{Ta}^{25}$ is high enough to influence the overall rate of reaction by a vapor transport mechanism.

Thus, the experimental findings are consistent with a purely solid state mechanism. It is not unexpected that $\mathrm{Ta}_{2} \mathrm{C}$ was observed first before the formation of $\mathrm{TaC}$ in reaction. Both self diffusion and chemical diffusion coefficients have been measured in $\mathrm{TaC}^{26}$. These measurements indicate that 
in the temperature range of interest $1700-2000{ }^{\circ} \mathrm{C}$ the carbon atom diffuses several orders of magnitude faster than the Ta atom in TaC. Therefore, as carbon diffuses into the Ta lattice, a dilute solid solution is formed. Then, as more carbon diffused into the Ta the concentration level of $\mathrm{C}$ is raised high enough for the formation of $\mathrm{Ta}_{2} \mathrm{C}$. In the $\mathrm{Ta}_{2} \mathrm{C}$ structure $(\mathrm{P} 63 / \mathrm{mmc})$ there are two octahedral interstices on either side of a hexagonal layer. These are located directly above one another, and only one of these can be occupied. That is, only one-half of the octahedral interstices in $\mathrm{Ta}_{2} \mathrm{C}$ is filled ${ }^{27}$. Further, carbon diffused into the subcarbide lattice would have to be accommodated by a hexagonal-to-cubic transformation to the $\mathrm{TaC}$ phase, in which all octahedral sites can now be occupied. However, if there were just enough carbon to form the subcarbide as in reaction II, the final product would just be $\mathrm{Ta}_{2} \mathrm{C}$ as was observed in reaction II.

Within the time resolution of our synchrotron diffraction experiments no intermediate phase is observed in the $2 \mathrm{Ta}+\mathrm{C}$ reaction. Again, the direct conversion of the stoichiometric powder mixture to $\mathrm{Ta}_{2} \mathrm{C}$ is consistent with the phase diagram which shows only the two compounds. Finally, the formation of $\mathrm{Ta}_{2} \mathrm{C}$ proceeds by a factor of $\sim 2$ faster than for the formation of $\mathrm{TaC}$, as indicated by the steeper slopes of the $\mathrm{Ta}_{2} \mathrm{C}$ concentration profiles (Figs. 9 and 10) as compared with that for the $\mathrm{TaC}$ formation (Fig. 9). This in turn suggests that the diffusion rate of carbon to the Ta metal lattice to form the $\mathrm{Ta}_{2} \mathrm{C}$ hexagonal phase is a factor of two faster than the rate of carbon diffusion in the $\mathrm{Ta}_{2} \mathrm{C}$ lattice in transforming to the final $\mathrm{TaC}$ product. It is challenging to elucidate the mechanism of each of these reactions to further our understanding of the observed reaction times.

\subsection{Phase distribution in the Heat-affected zone of Ti fusion welds}

In the following, the five principal diffraction patterns will be discussed in light of the associated microstructure at various locations in the HAZ and its vicinity during the welding process.

\subsubsection{The $\alpha_{A R}$ pattern: location and associated microstructure}


The locations at which the $\alpha_{\mathrm{AR}}$ pattern was observed are plotted in Fig. 11a. The corresponding diffraction pattern is shown in Fig. 11b. Profile analysis revealed that the peak width of the $\alpha_{\mathrm{AR}}$ patterns appearing at the end of each of the SRXRD scans was narrower than the room temperature base metal peak width. This implies that none of the SRXRD scans were measured far enough out to reach the unaffected titanium base metal.

Polycrystalline titanium base metal starts with small diffraction domains and grains that exhibit a high degree of disorder and internal stress due to the extrusion and machining process. Stresses and disorder result in broad single peaks originating from diffraction domains with sizes in the order of $20 \mathrm{~nm}$. Domain sizes were obtained from the Scherrer formula ${ }^{28}$ $\left(t=0.9 \lambda /\left(v_{h k l} \cos \left(\Theta_{h k l}\right)\right)\right.$, with $t$ the thickness of a diffraction domain, $\lambda$ the wavelength, and $v_{\mathrm{hkl}}$ and $\Theta_{\mathrm{hkl}}$ the peak width (in radiant) and Bragg angle of the (hkl) line, respectively. Thus, diffraction domain sizes were calculated to compare different phases and evaluate relative microstructural changes, but not to obtain absolute values.

Moving towards the center of the weld in $x$ and $y$, annealing of the base metal takes place with increasing temperature. Defects and stress in the grains are being reduced and small diffraction domains grow to form larger, more perfect domains. This results in a progressive narrowing of diffraction peaks along the positive temperature gradient. Fig. 12 shows the variation of the $\alpha$-Ti (002) peak width for two experimental runs ahead of the weld center at position $x=-8$ and $-7 \mathrm{~mm}$. The $y$ scales of these two SRXRD runs were combined employing the simplified heat-flow model $^{19}$. Peak width narrowing is given as difference between the $\alpha$-Ti (002) peak width of the base metal at room temperature and the $\alpha_{A R}(002)$ peak width at temperature. As can be seen from Fig. 12, the variation of the (002) peak width as a function of $y$-coordinates along a positive 
thermal gradient towards the weld center proceeds via a minimum in domain size. This suggests a three step mechanism, where the following three steps can be distinguished: (i) an initial annealing of defects and stress in the base metal and growth of diffraction domains resulting in a peak narrowing, (ii) a recrystallization process that yields smaller yet more perfect domains and leads to a broadening of diffraction peaks, (iii) subsequently a growth of diffraction domains which results in a narrowing of peaks eventually towards the $\alpha_{\mathrm{RG}}$ phase. These three regions are indicated in Fig. 11 by different shadings. The observed behavior is in good agreement with the conventional picture of annealing phenomena in metals which is believed to proceed via initial reduction of stress and number of defects, recrystallization, and grain growth. All these steps are evident in the measured diffraction patterns at temperature.

Anisotropy in the thermal expansion coefficients of hcp $\alpha$-titanium can be found in different peak shifts of the $\alpha$-Ti (101), (002), and (101) diffraction lines. $\alpha$-Ti is known to exhibit a larger thermal expansion in the $c$ direction perpendicular to the basal plane of the hexagonal lattice $^{29}$ than in the $a$ direction. For the $\alpha$-Ti (002) peak, for instance, a temperature difference of about $200 \mathrm{~K}$ should result in a peak shift of about 0.06 degrees in $2 \theta$ for the scattering geometry used (thermal expansion coefficient $C_{a}=7.5 * 10^{-6} \mathrm{~K}^{-1}$ in the $a$ direction and $C_{c}=1.1 * 10^{-5} \mathrm{~K}^{-1}$ in the $c$ direction $^{31}$ yield $C_{(002)}=3.0^{*} 10^{-4} \mathrm{O}(2 \theta) / \mathrm{K}$ for $(002)$ line). Calculation of relative diffraction plane $d$ spacing expansion for the three $\alpha$-Ti $(101,002,102)$ peaks seen in the SRXRD data yields the largest effect on the (102) diffraction peak $\left(C_{(101)}<C_{(002)}<C_{(102)}\right.$; with $C_{(102)}$ being $\sim 20 \%$ more than $C_{(002)}$ and $\sim 30 \%$ more than $\left.C_{(101)}\right)$. Fig. 13 shows the peak shift of the three (hkl) $\alpha$-Ti peaks with temperature for an experimental SRXRD run at a position of $x=-2$ with respect to the weld center. (hkl) peak positions were determined from a least-squares fit of a Gaussian profile 
function to the individual diffraction peaks. Temperature data were taken from the simplified heat flow model. For clarification, the difference of (hkl) peak positions at elevated temperature and at room temperature is displayed. Different expansion coefficients $C_{(h k l)}$ for different directions in the $\alpha$-Ti lattice (Fig. 18) can be seen from different slopes of the corresponding curves. A linear fit to each curve in Fig. 13 yields expansion coefficients in terms of diffraction angle $2 \theta$ of $C_{(002)}=$ $2.0^{*} 10^{-3} \mathrm{O}(2 \theta) / \mathrm{K}, C_{(101)}=1.5^{*} 10^{-3} \mathrm{O}(2 \theta) / \mathrm{K}$, and $C_{(102)}=2.5^{*} 10^{-3} \mathrm{o}_{(2 \theta) / \mathrm{K}}$. The qualitative difference between the $C_{(h k l)}$ expansion coefficients is in agreement with the above-mentioned considerations $\left(C_{(101)}<C_{(002)}<C_{(102)}\right)$, with the ratio between $C_{(101)}$ and $C_{(102)}$ of 0.6 being slightly higher than the calculated difference of $\sim 30 \%$. Furthermore, the experimental absolute values exceed the expected ones by one order of magnitude. This might be due to an additional peak shift caused by a slight wobbling motion of the titanium bar during the experiment.

\subsubsection{The $\alpha_{R G}$ pattern: location and associated microstructure}

The locations at which the $\alpha_{R G}$ pattern was observed are plotted in Fig. 14a. The corresponding diffraction pattern is shown in Fig. 14b. Further annealing and growth of $\alpha$-Ti diffraction domains are expected with increasing temperature towards the weld center. The process can indeed be observed in a continuous decrease in diffraction peak width, which eventually leads to a transition from $\alpha_{\mathrm{AR}}$ to $\alpha_{\mathrm{RG}}$ patterns. $\alpha$-Ti diffraction patterns from inside the HAZ (915 ${ }^{\mathrm{O}} \mathrm{C}$ isotherm) correspond to $\alpha+\beta$ coexistence regions. Different kinetic mechanisms that govern $\alpha \rightarrow$ $\beta$ and $\beta \rightarrow \alpha$ phase transformation ahead and behind the center of the weld, respectively, are responsible for the occurrence of $\alpha$-Ti beyond the phase transformation isotherm on the heating side of the weld ${ }^{19}$. 
Similar to the $\alpha_{\mathrm{AR}}$ pattern, the observed $\alpha_{\mathrm{RG}}$ pattern also exhibits a strong (002) intensity due to texture of the base metal, and a low angle shoulder due to contribution of $\mathrm{TiO}_{\mathrm{x}}$ phases. However, the integrated intensity of the $\mathrm{TiO}_{\mathrm{x}}$ peak seems to be larger for $\alpha_{\mathrm{RG}}$ patterns compared to the base metal. Two reasons can account for this observation. Firstly, diffusion and segregation of oxygen into the existing $\mathrm{TiO}_{\mathrm{x}}$ layer and annealing of the same, might result in an increase of $\mathrm{TiO}_{\mathrm{x}}$ peak intensity. Secondly, in the coexistence region with $\beta$-Ti (Fig. 14b), oxygen from titanium particles that already have been transformed to $\beta$-Ti diffuses to the remaining $\alpha-\mathrm{Ti}$, which has a higher oxygen solubility, resulting in an increase of the $\mathrm{TiO}_{\mathrm{x}}$ contribution to the $\alpha$-Ti diffraction peaks. Additionally, a distinction of $\mathrm{TiO}_{\mathrm{x} 1}$ and $\mathrm{TiO}_{\mathrm{x} 2}$ diffraction peaks (Fig. 15) as previously reported $^{12}$ is possible at this state of annealing and grain growth of $\alpha$-Ti. An $\alpha_{R G}$ diffraction domain thickness of about $300 \mathrm{~nm}$ was estimated from single 'spike' width obtained from a leastsquares fit of several Gaussian function to one Bragg peak (Fig. 15). Due to the limited number of data points, peak widths ( 5 in number) were refined to vary the same plus two extra peaks for $\mathrm{TiO}_{\mathrm{x} 1}$ and $\mathrm{TiO}_{\mathrm{x} 2}$ shoulders.

\subsubsection{The $\beta$ and $\beta_{L}$ patterns: location and associated microstructure}

The locations at which the $\beta$ and $\beta_{\mathrm{L}}$ pattern were observed are plotted in Fig. 16a. The corresponding diffraction pattern is shown in Fig. 16b. At temperatures above the $915{ }^{\circ} \mathrm{C} \alpha \rightarrow \beta$ phase transformation isotherm $\beta$-Ti becomes the thermodynamically more stable titanium phase. In the vicinity $\sim 2.0 \mathrm{~mm}$ of the liquid weld pool and on the backside of the HAZ, 'pure' $\beta$-Ti diffraction patterns are observed (Fig. 16). Further out in the colder region but still in the HAZ, a large coexistence region with $\alpha$-Ti can be found ahead of the liquid weld pool, whereas this region 
appears to narrow with $x$. The transformation kinetics (hence mechanism) on the leading side of the liquid pool with thermal gradients $\sim 100 \mathrm{~K} / \mathrm{mm}$ may be very different from that of the back side having a lower thermal gradient. Such difference in kinetics is largely responsible for the variation in spatial extent of the $\alpha+\beta$ coexistence regions in the HAZ ${ }^{19}$.

Large $\beta$-Ti diffraction domains in the hot region of the HAZ lead to strong and very narrow diffraction peaks (Fig. 16b). Again, splitting within a given diffraction peak similar to those discussed for the $\alpha_{R G}$ pattern is observed. Since the $\beta$-Ti grains seem to grow larger than $\alpha$-Ti grains particularly in the hot region of the HAZ near the weld pool, generally only one or two 'spikes' can be observed with an occasionally missing of all diffraction peaks. Similar to the base metal $\alpha$-Ti patterns, the $\beta$-Ti patterns also show a preferred orientation in the diffraction patterns. On the average, most patterns showing a strong (110) peak and only a small or no (200) peak can be found in the experimental data. This might be inherited from the preferred orientation of the $\alpha$ Ti phase in (002) direction. In the $\alpha \rightarrow \beta$ phase transformation the most densely packed hcp layer (basal plane (002)) in $\alpha$ titanium becomes the most densely packed layer in the $\beta$ titanium bcc structure leading to a preferred orientation of large $\beta$ grains in the (110) direction of the cubic $\beta$-Ti lattice. Furthermore, the size of $\beta$ diffraction domains in the colder part of the HAZ right after the phase transformation has taken place, amounts to ca. $300 \mathrm{~nm}$ as calculated from diffraction peak width obtained from profile refinement to a multiplet (200) peak. This value is in good agreement with the diffraction domain size of $\alpha_{\mathrm{RG}}$-Ti prior to phase transformation, and substantiate the fact that the entire $\alpha$-Ti grain transforms to $\beta$-Ti and retains its grain size upon phase transformation. This corroborates the idea of maintaining the most dense layer in hep $\alpha$-Ti and bcc $\beta$-Ti upon transformation as cause for the observed texture in $\beta$-Ti. 
Besides diffraction patterns exhibiting strong $\beta$-Ti peaks, a low intensity (110) $\beta_{\mathrm{L}}$ peak is also observed usually in coexistence with the $\alpha_{R G}$ pattern (Fig. 14). The $\beta_{L}$ pattern extends over a considerably long range in the $y$ direction. The underlying microstructures that belong to locations on the map showing $\beta_{\mathrm{L}}$ diffraction patterns have to be divided into two different phases. Diffraction data taken below a straight line drawn from the maximum of the $915{ }^{\circ} \mathrm{C}$ isotherm in $y$ parallel to $x$ (Fig. 16) belong to residual $\beta$-Ti that was not completely back transformed to $\alpha$-Ti. This residual $\beta$-Ti stems from region in the HAZ were the phase transformation temperature was exceeded. The ratio of integrated intensities of (110) $\beta_{\mathrm{L}}$ peak and (002) $\alpha_{\mathrm{BT}}$ peak amounts to ca. 0.1. In contrast, (110) $\beta_{\mathrm{L}}$ peaks measured above the maximum of the $915{ }^{\mathrm{O}} \mathrm{C}$ isotherm in $y$ correspond to $\alpha$-Ti that had already started to but did not completely transform to $\beta$-Ti. The early onset of the transformation can be explained by a slightly lowered $\alpha \rightarrow \beta$ transformation temperature in the vicinity of bcc nucleation sites within the material or due to impurities in the titanium $^{19}$.

\subsubsection{The $\alpha_{B T}$ pattern: location and associated microstructure}

The locations at which the $\alpha_{\mathrm{BT}}$ pattern was observed are plotted in Fig. 17(a). The corresponding diffraction pattern is shown in Fig. 17(b). This new $\alpha_{\mathrm{BT}}$ pattern is found behind the " $\beta$-pattern" region and outside the HAZ (Fig. 20), and is associated with a new microstructure of $\alpha$-Ti. This pattern corresponds to $\alpha$-Ti that has been back transformed from $\beta$-Ti formed in the HAZ around the weld. Compared to the $\alpha_{\mathrm{RG}}$ and the $\beta$ pattern, the $\alpha_{\mathrm{BT}}$ pattern in Fig. 20 shows no multiple diffraction line and the line width is in the same range as the $\alpha_{\mathrm{AR}}$ pattern. The size of $\alpha_{\text {BT }}$ phase diffraction domains amounts to about $100 \mathrm{~nm}$ as obtained from the Scherrer formula. 
Since the $\alpha_{\text {BT }}$ phase stems from large $\beta$ grains in the HAZ, it implies that the size of the $\beta$-Ti diffraction domains is not retained upon back transformation to $\alpha$-Ti. This in turn suggest that large $\beta$ domains break up into smaller $\alpha$-Ti domains during the back transformation.

Another characteristic of the $\alpha_{\mathrm{BT}}$ pattern is the absence of a distinct low angle shoulder due to contributions of $\mathrm{TiO}_{\mathrm{x}}$. This corroborates the assumption of $\mathrm{TiO}_{\mathrm{x}}$ diffraction peaks originating from surface oxidized base metal or oxygen impurities rather than oxidation of the metal during welding. The $\alpha \rightarrow \beta$ phase transformation results in oxygen diffusion from the forming $\beta$-Ti grains to remaining $\alpha$-Ti base metal grains owing to a higher solubility of oxygen in $\alpha$-Ti. Therefore, $\beta \rightarrow$ $\alpha$ back transformation affords low oxygen $\alpha$-Ti that shows no distinct contribution of $\mathrm{TiO}_{\mathrm{x}}$. This region stems from the $\alpha+\beta$ coexistence region in the $\operatorname{HAZ}(\mathrm{y}=9$ to $10 \mathrm{~mm})$ that results in a mixed zone upon $\beta \rightarrow \alpha$ back transformation containing $\alpha$-Ti that has never been transformed to $\beta$-Ti and back transformed $\alpha$-Ti. Diffraction patterns belonging to this coexistence region can be identified by the occurrence of a low angle $\mathrm{TiO}_{\mathrm{x}}$ shoulder together with a distinct (101) preferred orientation and the presence of (100) and (110) $\alpha$-Ti peaks. Fig. 18 shows a comparison of a $\alpha_{\mathrm{BT}}$ diffraction pattern and a coexistence pattern. A low angle shoulder can be seen at the (002) peak of the coexistence pattern, whereas the $\sigma \tau \rho 0 v \gamma(101)$ peak in both the coexistence and the $\alpha_{\mathrm{BT}}$ pattern exhibits a symmetric profile without a low angle shoulder. Additionally, the $\alpha_{\mathrm{BT}}$ pattern exhibits low $\beta$ (110) peak due to residual amounts of $\beta$-Ti behind the HAZ of the weld.

\section{Concluding Remarks}

In this paper we have described a couple of synchrotron techniques and extended our experimental capability to probe materials processing in both the time domain and spatial regime. In 
the case of solid combustion syntheses of $\mathrm{TaC}$ and $\mathrm{Ta}_{2} \mathrm{C}$, the chemical dynamics of the combustion front has been elucidated with a time-resolution of $50 \mathrm{~ms}$ time frames by monitoring $\mathrm{x}$-ray diffraction patterns of the reactants and products with synchrotron radiation. The synthesis of TaC from a stoichiometric 1:1 mixture of $\mathrm{Ta}$ and $\mathrm{C}$ is preceded by the formation of $\mathrm{Ta}_{2} \mathrm{C}$, the concentration of which decreases with time as the diffusion controlled process proceeds to completion. Formation of $\mathrm{Ta}_{2} \mathrm{C}$ from a 2:1 mixture of $\mathrm{Ta}$ and $\mathrm{C}$ is straightforward and occurs almost immediately with no indication of any other products. These results clearly demonstrate usefulness of the TRXRD technique using intense synchrotron radiation to monitor phase transformation and high temperature solid state processes down to the milliseconds time regime not readily possible with conventional means.

The SRXRD results for Ti fusion welds illustrate the another novelty of the synchrotron diffraction method to map solid-state phases and their boundaries in-situ with sub-millimeter spatial resolution $(\sim 200 \mu \mathrm{m})$ during materials processing at temperature and in real time. Spatially resolved and dynamic structural information of this sort, not readily obtainable with either conventional structural techniques (due to their ex-situ and post-mortem nature) or simple heat flow calculations $^{11,19}$, must be taken into account for qualitative understanding and quantitative modeling of phase transformation kinetics and microstructural evolution in systems under highly non-isothermal

conditions $^{30}$. Finally, improved experimentations such as a smaller beam spot emitted from $3^{\text {rd }}$ generation synchrotron sources, better mechanical stability (tighter scattering geometry) and use of areal detector would enable more quantitative structural information for future materials dynamic studies exemplified by this work.

\section{Acknowledgment}

This work was performed under the auspices of the US Department of Energy (DOE), Lawrence Livermore National Laboratory, under contract W-7405-ENG-48. We would like to thank P. A. Waide for technical assistance in designing and fabrication of the reaction chambers 
used in the work. The synchrotron experiments were carried out at both the National Synchrotron Light Source at Brookhaven and Stanford Synchrotron Radiation Laboratory supported by DOE, Division of Chemical Sciences.

\section{Notes and References}

Current addresses: (a) Grand Canyon University, College of Science, 3300 W. Camelback Rd, Phoenix, AZ 85107; (b) 3908 Freed Ave, San Jose CA 95117; and (c) Fritz-Haber-Institute of the Max-Planck-Society, Department of Inorganic Chemistry, Faradayweg 4-6, D-14195 Berlin, Germany.

1. (a) Z.A. Munir, Ceramic Bulletin, 67(2), 342 (1988); (b) Z.A. Munir and U. Anselmi Tamburini, Mater. Sc. Rept. 3, 277 (1989).

2. A. G. Merzhanov, in "Combustion and Plasma Synthesis of High-Temperature Materials", Ed. by Z. A. Munir \& J. B. Holt, (1990) pp 1-53.

3. A.G. Merzhanov, Ceram. Trans. 13, 519 (1990).

4. J.-P. Lebrat and A. Varma, Physica C 184, 220-228 (1991)

5. V.V. Boldyrev and V. Aleksandrov, Dok. Akad. Nauk. SSSR 259, 1127 (1981). 
6. Joe Wong, E. M. Larson, J. B. Holt, P. Waide, B. Rupp \& R. Frahm, Science 249,1406 (1990).

7. R. Frahm, Joe Wong, J.B. Holt, E.M. Larson, B. Rupp and P.A. Waide, Phys. Rev. B46, 9205 (1992).

8. International Trends in Welding Science and Technology, ed. S.A David and J.M. Vitek, ASM Intern., 1993.

9. B.K. Damkroger, G.R. Edwards, and B.B. Rath, Welding Journal, 68, 290 (1989).

10. M.C. Mcguire, M.L. Santella, B.K. Damkroger, The Science of Metal Joining, ed. by M. H., Cieslak, J. Perepezko, S. Kang and M.E. Glicksman, TMS (1992), 41.

11. J.W. Elmer, Joe Wong, M. Froeba, P.A. Waide, E.M. Larson, Met. Mat. Trans. 27A, 775 (1996).

12. Joe Wong, E. M. Larson, J.B. Holt, P.A. Waide, B. Rupp, R. Frahm, Science 249, 1406 (1990).

13. "Binary Alloy Phase Diagrams" eds. T.B. Massalski, J.L. Muray, L.H. Bennett, H. Baker, ASM, Vol. 1 (1986).

14. V. M. Shkiro, G. A. Nersisyan \& I. P. Borovinskaya, Fiz. Goreniya Vzryva, 14, 58, (1978).

15. V. M. Shkiro, G. A. Nersisyan, I. P. Borovinskaya, A. G. Merzhanev \& V. Sh. Shokhtman, Poroshkovaya Metallurgiya, 4, 14, (1979).

16. V. M. Shkiro \& G. A. Nersisyan, Fiz. Goreniya Vzryva, 14, 149, (1978).

17. E.M. Larson, Joe Wong, J.B. Holt, P.A. Waide, B. Rupp and L.J.Terminello, J. Mat. Res. 8, 133 (1993).

18. T. Ressler, Joe Wong and J.W. Elmer, J. Phys. Chem. B. 102(52), 10724 (1998).

19. J.W. Elmer, Joe Wong and T. Ressler, Met. Mater. Trans. 29A, 2761 (1998).

20. E. M. Larson, P. A. Waide \& Joe Wong, Rev. Sci. Instrum. , 62(1), 53-7, (1991).

21. V. Karpenko, J.H. Kinney, S. Kulkarni, K. Neufeld, C. Poppe, K.G. Tirsell, Joe Wong, J. Cerino, T. Troxel, J. Yang, E. Hoyer, M. Green, D. Humpries, S. Marks, D. Plate, Rev. Sci. Instrum., 60, 1451 (1989).

22. E.M. Larson, P.A Waide, Joe Wong, Rev. Sci. Instrum., 62, 53 (1991)/

23. M. Donachie, Titanium A Technical Guide, ASM International, 1989.

24. A. A. Gavrish, M. P. Glazunov, Yu. M. Korolev, V. I. Spitsyn \& G. K. Fedoseev, Russ. J. 
Inorg. Chem., 20, 1269, (1975).

25. R.E. Bolz and G.L. Ture, Handbook of Tables for Appl. Eng. Sc., The Chemical Rubber Co., (1970) p. D-173

26. I. I. Spivak \& V. V. Klimenko, Fiz. Metal. Metalloved. 32, 314, (1971).

27. A.F. Wells, Structural Inorganic Chemistry, Oxford Univ. Press, 4th Ed. (1975), p. 760.

28. D. Cullity, Elements of x-ray diffraction, 3rd ed.; Addison and Wesley, New York, 1967.

29. N. Schmitz-Pranghe and P. Duenner, Z. Metallkde, 59, 377 (1968).

30. Z. Yang, J.W. Elmer, Joe Wong and T. DebRoy, The Welding Journal, (1999), in press.

\section{Figure Captions}

Fig. 1 Schematic diagram showing the TRXRD diffractometer reaction chamber setup at NSLS Beamline $\mathrm{X}-11^{17,20}$.

Fig. 2 Schematics of the SRXRD setup used for in-situ phase mapping and real-time observation of microstructure evolution in fusion welds ${ }^{12}$.

Fig. 3. Schematic representation of the SRXRD procedure used. Indicated are HAZ (limited by $915{ }^{\circ} \mathrm{C}$ isotherm) and FZ (limited by $1670{ }^{\circ} \mathrm{C}$ isotherm) as determined from heat-flow model calculations $^{19}$, and the direction of movement of the titanium material underneath the tungsten electrode (black dot at $\mathrm{x}=0.0 \mathrm{~mm}$ and $\mathrm{y}=0.0 \mathrm{~mm}$ ). Each dotted arrow represents a single experimental SRXRD run, and each dot denotes an x-ray diffraction pattern measured at this location. Heating and cooling side of the moving weld are indicated.

Fig. 4 A 3-dimensional plot of the time-resolved diffraction patterns for the combustion reaction: Ta $+\mathrm{C} \rightarrow \mathrm{TaC}$ collected at $100 \mathrm{~ms} / \mathrm{scan}$. Only every 10th scan was plotted for visual clarity. $\mathrm{t}=0.0 \mathrm{~s}$ corresponds to triggering of the detectors. Beyond 20s the TRXRD patterns remained unchanged.

Fig. 5 Selected TRXRD patterns collected at $100 \mathrm{~ms} / \mathrm{scan}$ for the $\mathrm{Ta}+\mathrm{C} \rightarrow \mathrm{TaC}$ combustion reaction, showing critical events in the course of the reaction. Time $=0.0$ seconds corresponds to triggering of the detectors.

Fig. 6 Selected TRXRD patterns collected at $50 \mathrm{~ms} / \mathrm{scan}$ for the $2 \mathrm{Ta}+\mathrm{C} \rightarrow \mathrm{Ta}_{2} \mathrm{C}$ combustion 
reaction, showing critical events in the course of the reaction. Time $=0.0$ seconds corresponds to triggering of the detectors.

Fig. 7 A series of SRXRD patterns measured across the $\alpha \rightarrow \beta$ phase transformation isotherm $(\mathrm{T}=$ $915^{\mathrm{O}} \mathrm{C}$ ) in the $\mathrm{y}$-direction along the negative temperature gradient at a position $\mathrm{x}=-6 \mathrm{~mm}$ ahead of the center of the weld (dotted arrow in inset) showing the $\beta-\mathrm{Ti}, \beta+\alpha$ coexistence, and $\alpha$-Ti zones.

Fig. 8 Principal diffraction patterns obtained from the current SRXRD measurement on titanium fusion welds. $(\alpha)$ represent the base metal hep $\alpha$-Ti phase. $\left(\alpha_{\mathrm{AR}}\right)$ is for the annealed and recrystallized $\alpha$-Ti. $\left(\alpha_{\mathrm{RG}}\right)$ denotes a recrystallized $\alpha$-Ti phase exhibiting large diffraction domains (grain growth). $\left(\alpha_{\mathrm{BT}}\right)$ is for the back transformed $\alpha$-Ti that forms from the region of the HAZ that once contained $\beta$-Ti. $(\beta)$ is for the $\beta$-Ti phase and $\left(\beta_{\mathrm{L}}\right)$ is for the $\beta$-Ti that coexists with $\alpha$-Ti in low amounts predominantly together with $\alpha_{\mathrm{BT}}$. The z-axis in the plot represents a line, $\mathrm{y}=7 \mathrm{~mm}$ parallel to the centerline of the weld as shown in Fig. 5 inset, that would yield this series of six SRXRD patterns. Data were normalized to unity for the highest peak in each pattern.

Fig. 9 Normalized integrated intensities plotted as a function of time for $\mathrm{Ta}(110), \mathrm{Ta}_{2} \mathrm{C}(101)$ and $\mathrm{TaC}(111)$ diffraction peaks, showing the chemical changes in the course of the $\mathrm{Ta}+\mathrm{C}$ reaction.

Fig. 10. Normalized integrated intensities plotted as a function of time for $\mathrm{Ta}(110)$ and $\mathrm{Ta}_{2} \mathrm{C}$ diffraction peaks, showing the chemical changes in the course of the $2 \mathrm{Ta}+\mathrm{C}$ reaction.

Fig. 11. (a) SRXRD map highlighting the locations at which the $\alpha_{\mathrm{AR}}$ pattern was observed in the vicinity of the HAZ during welding. Locations in the weld where annealing and recrystallization of the base material can be observed are indicated. (b) The corresponding diffraction pattern. Arrow in the inset indicates a low angle shoulder due to presence of a hexagonal $\mathrm{TiO}_{\mathrm{x}}$ phase (see text).

Fig. 12. Variation of (002) $\alpha$-Ti peak width as a function of $y$-coordinates along a positive thermal gradient obtained from two runs ahead of the weld at positions $x=-8$ and $-7 \mathrm{~mm}$. Plotted is the difference $\Delta(002)$ between $\alpha$-Ti base metal (002) peak width at $20{ }^{\circ} \mathrm{C}$ and $\alpha_{\mathrm{AR}}(002)$ peak width at temperature where an increasing $\Delta(002)$ reflects an increasing diffraction domain size.

Fig. 13. Evolution of $\alpha$-Ti diffraction peak positions with temperature measured at a position of $\mathrm{x}$ $=2 \mathrm{~mm}$ with respect to the weld (squares: (102), circles: (002), triangles: (101)). Plotted is the difference $\Delta(\mathrm{hkl})$ between the $\alpha_{\mathrm{AR}}(\mathrm{hkl})$ peak position at temperature and the $\alpha$-Ti base metal (hkl) peak position at room temperature. Temperature information were extracted from the simplified heat flow model.

Fig. 14. (a) SRXRD map highlighting the locations at which the $\alpha_{\text {RG }}$ pattern was observed in the vicinity of the HAZ during welding. Black bars inside the HAZ denotes regions of $\alpha+\beta$ coexistence. Dotted line indicates $\alpha_{\mathrm{RG}}$ and $\alpha_{\mathrm{BT}}$ coexistence zone (see text). (b) The corresponding diffraction pattern. Inset shows an enhanced $\mathrm{TiO}_{\mathrm{x}}$ shoulder together with a $\beta_{\mathrm{L}}(110)$ peak due to contribution of $\beta$-Ti. 
Fig. 15. Profile refinement of $\alpha$-Ti (002) peak in an $\alpha_{R G}$ diffraction pattern. Splitting of a single (002) Bragg peak is due to the scattering geometry used. Additional contribution of two different $\mathrm{TiO}_{\mathrm{x}}$ phases to a low angle shoulder is indicated. The five narrow peaks (with same refined peak width) are attributed to at least five large domains in $\alpha$-Ti diffracting into the photodiode.

Fig. 16. (a) SRXRD map highlighting the locations at which the $\beta$ and $\beta_{\mathrm{L}}$ pattern was observed in the vicinity of the HAZ during welding. (b) The corresponding $\beta$-Ti diffraction pattern.

Fig. 17. (a) SRXRD map highlighting the locations at which the $\alpha_{\mathrm{BT}}$ pattern was observed in the vicinity of the HAZ during welding. (b) The corresponding diffraction pattern. Arrow in inset indicates absence of $\alpha$-Ti (002) peak in this pattern.

Fig. 18. Comparison of $\alpha_{\mathrm{BT}}$ pattern from $\alpha$-Ti back transformed from HAZ $\beta$-Ti and a pattern from the boundary between $\alpha_{\mathrm{BT}}+\alpha_{\mathrm{RG}}$ regions. Indicated by arrows are residual amounts of $\beta$-Ti $\left(\beta_{\mathrm{L}}(110)\right)$ in the $\alpha_{\mathrm{BT}}$ pattern and a low angle shoulder due to $\mathrm{TiO}_{\mathrm{x}}$ contribution to $\alpha_{\mathrm{RG}}$ pattern. 


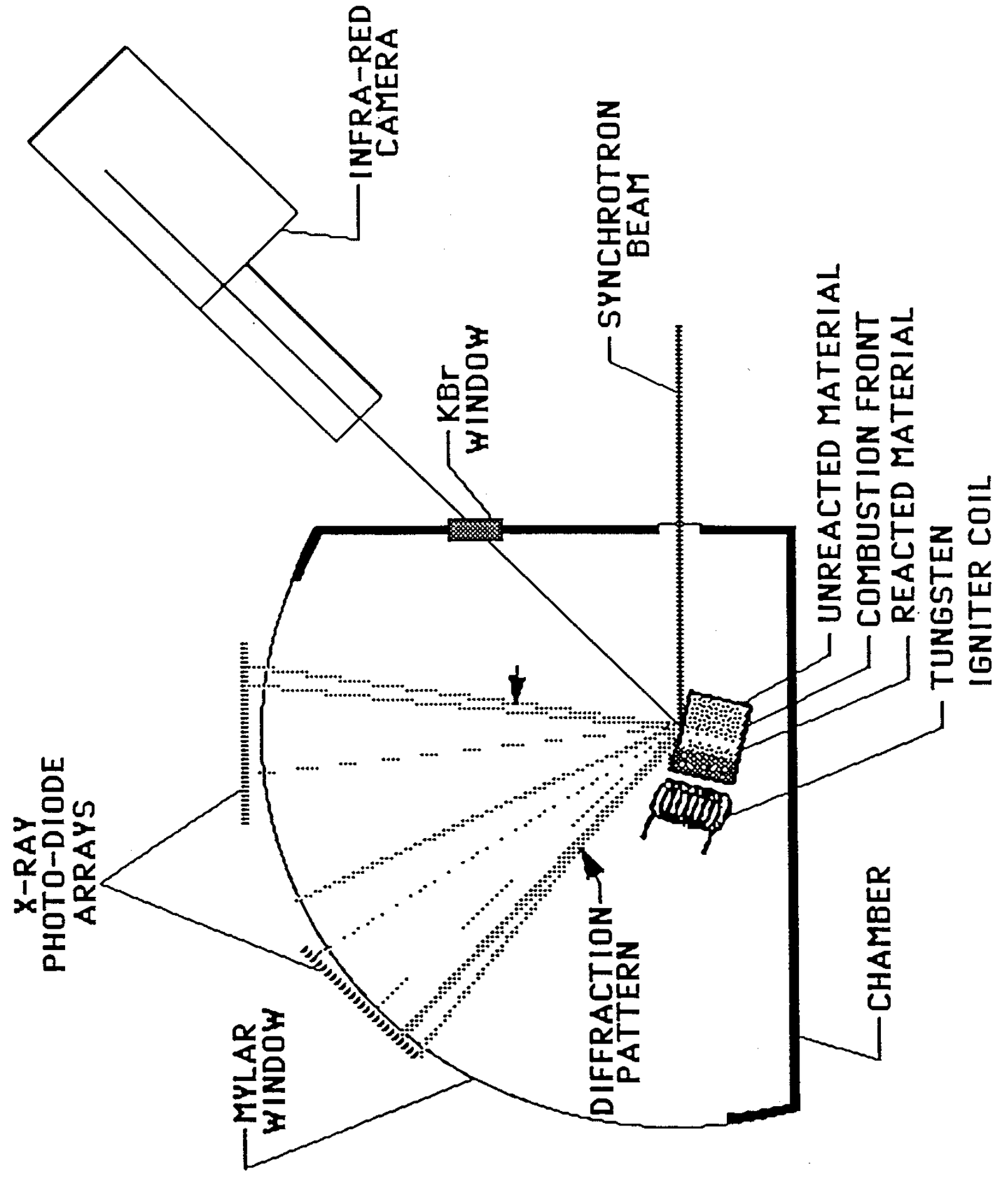


Fig. 2

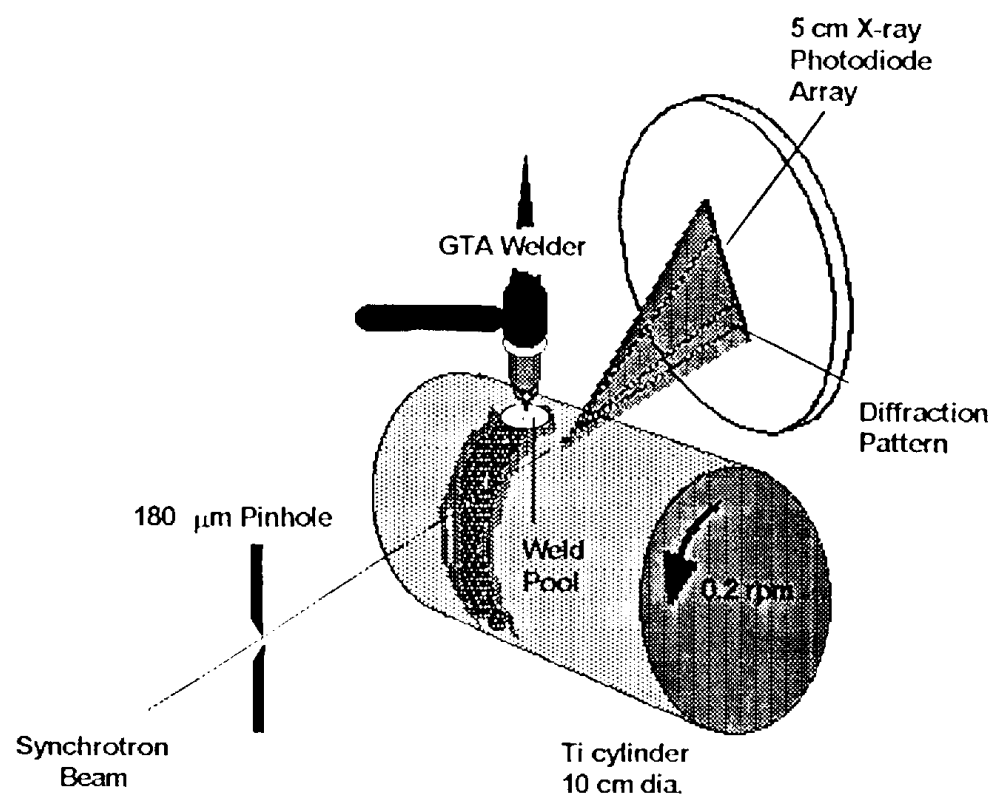


Fig. 3

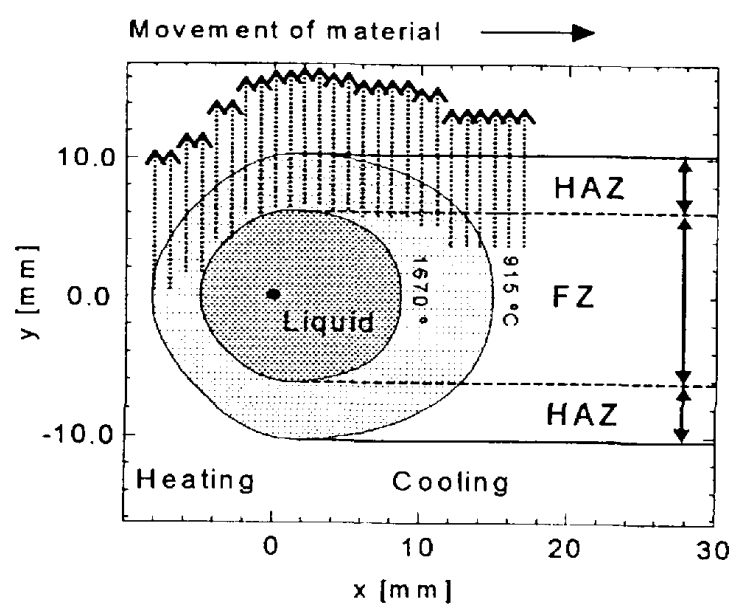




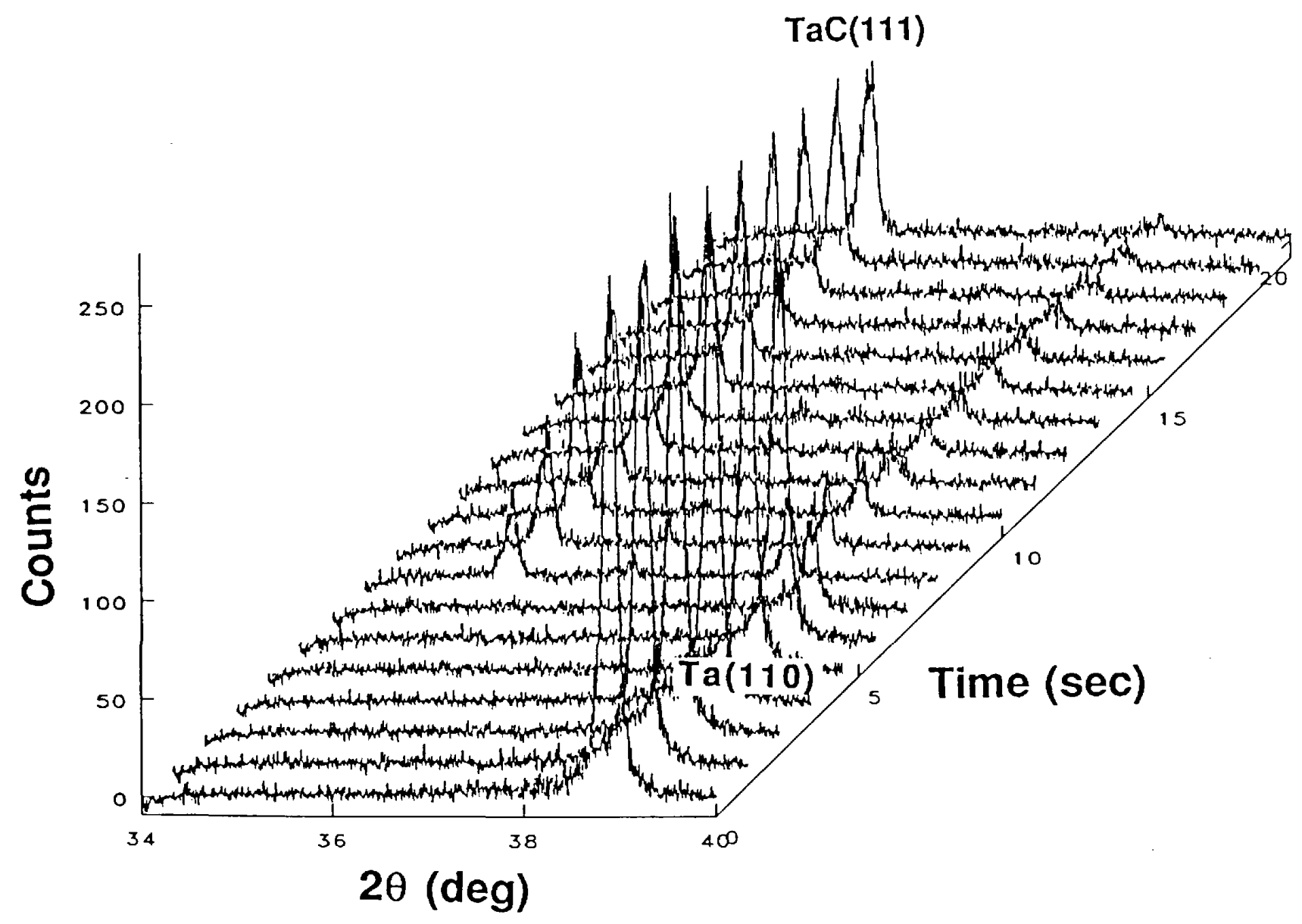

Jig. 4 


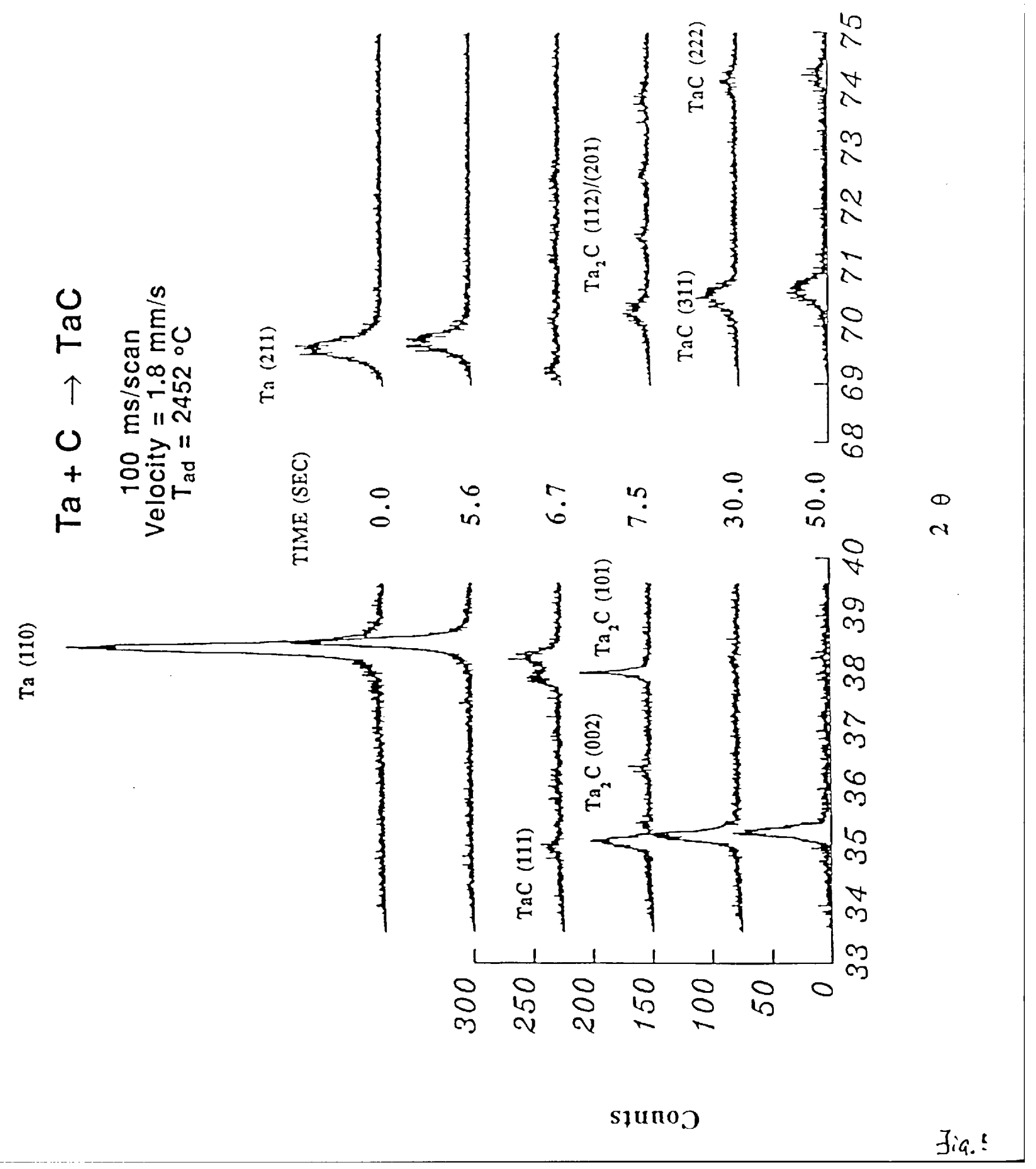




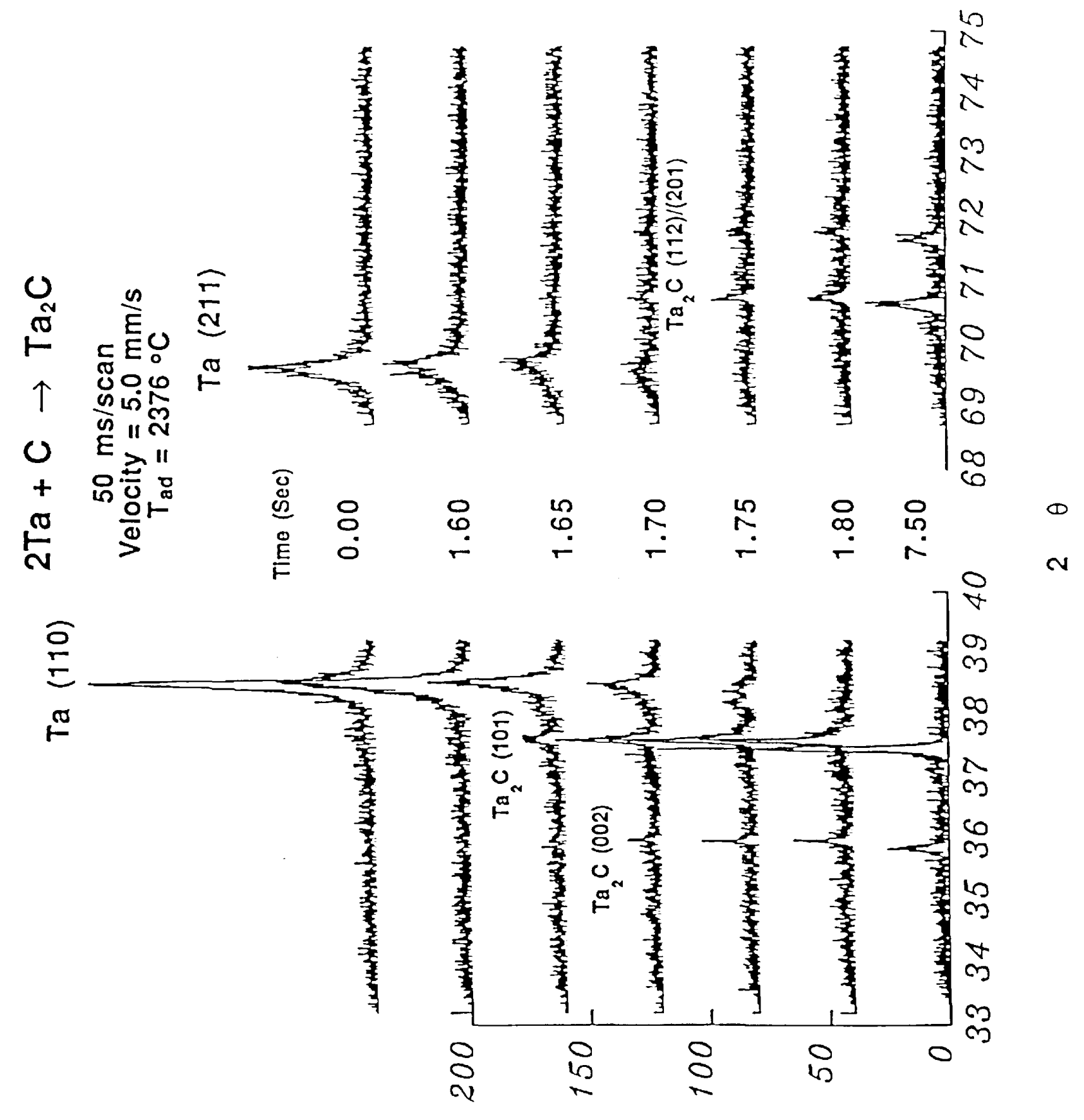

słunoo

Jig. 6 
Fig. 7
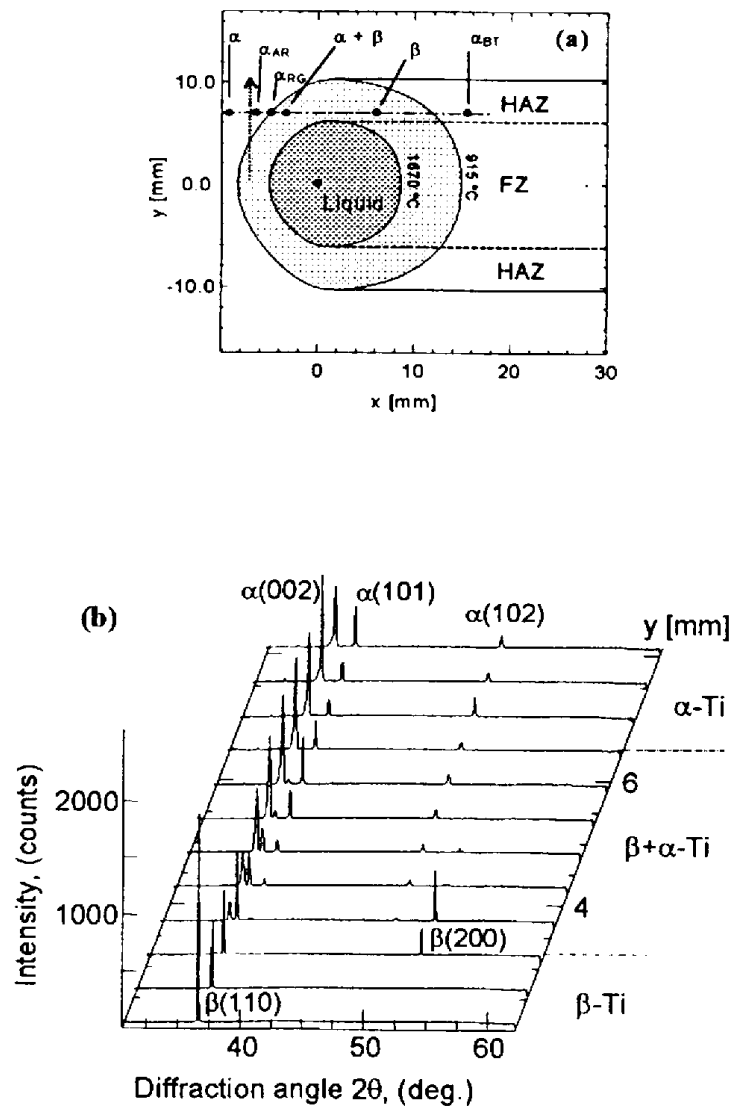
Fig. 8

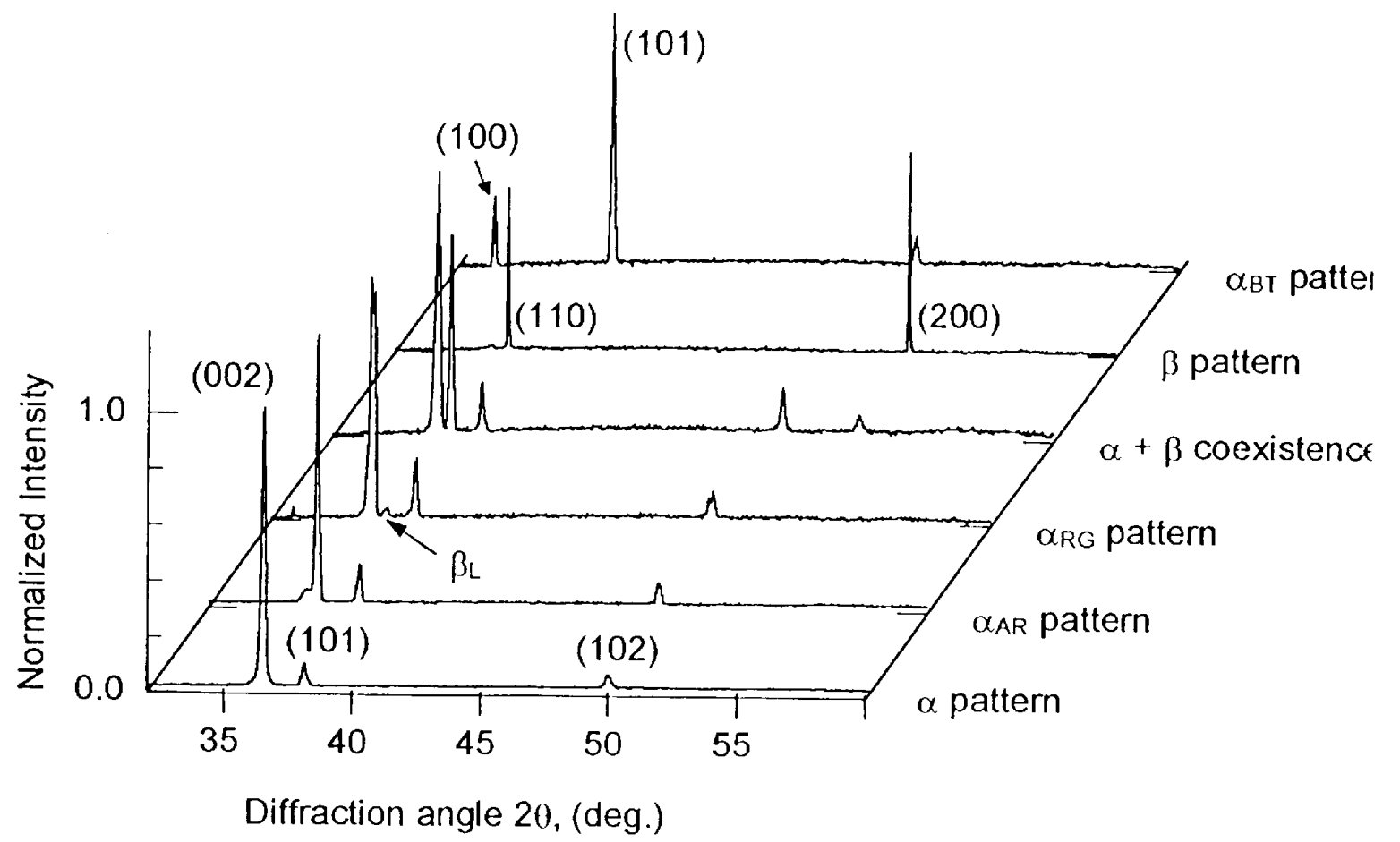




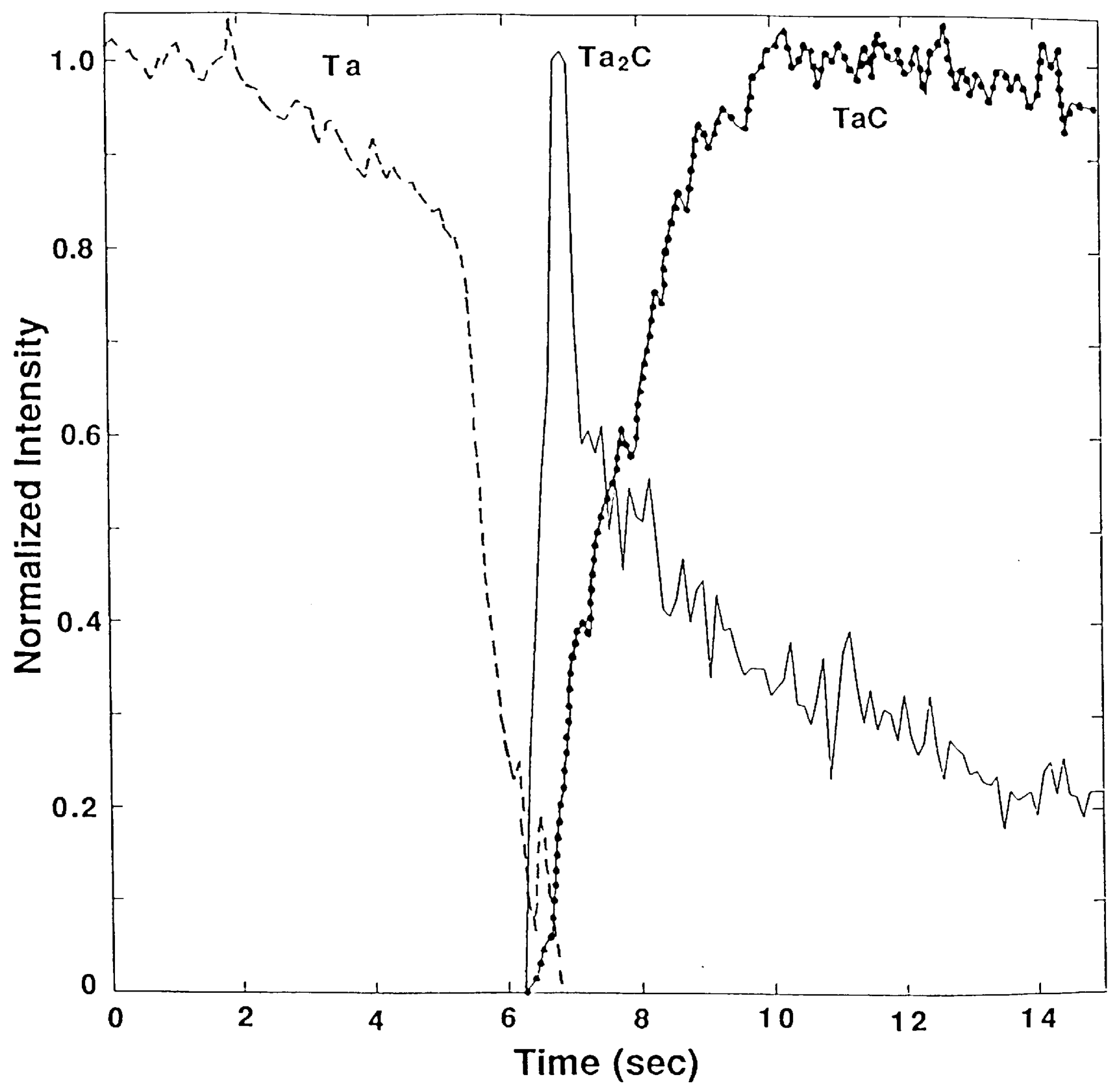

Fig. 9 


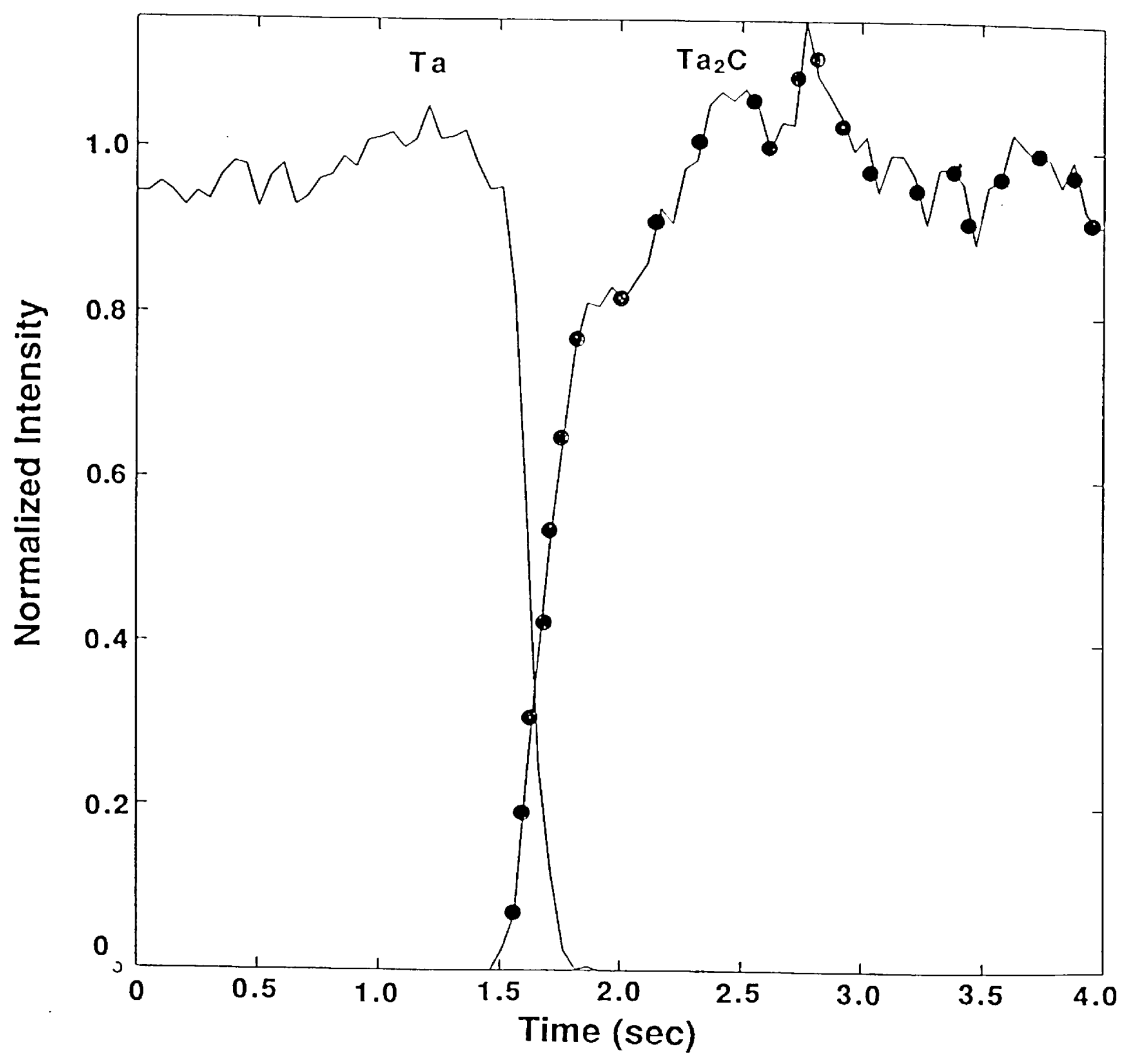

7 in 10 
Fig. 11
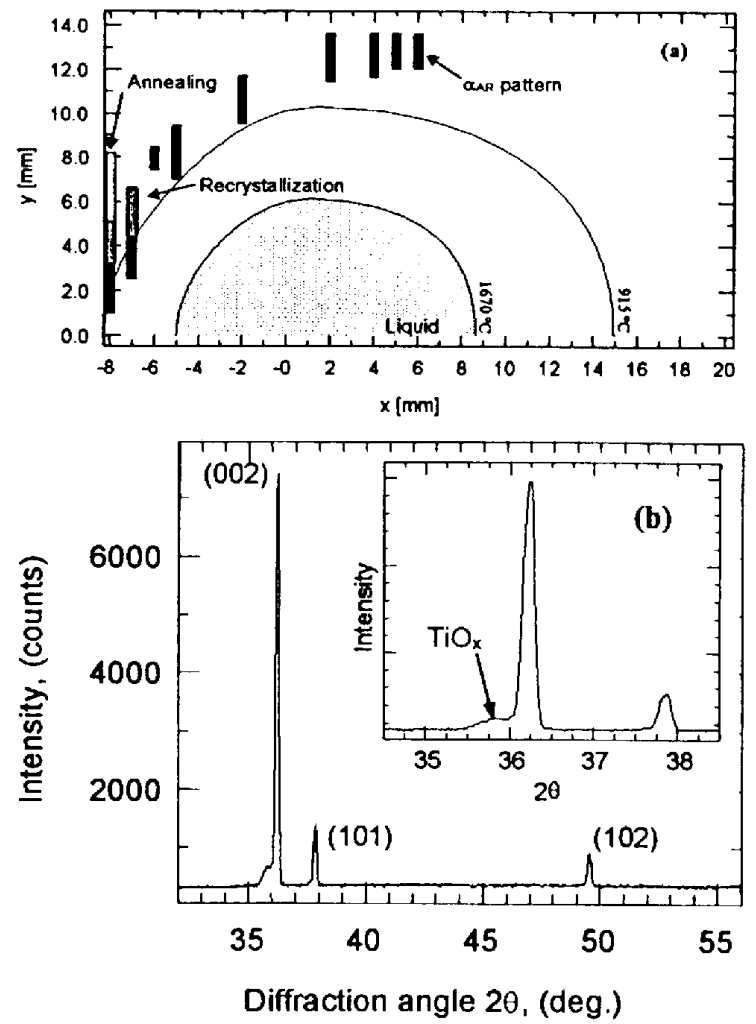

Fig. 12

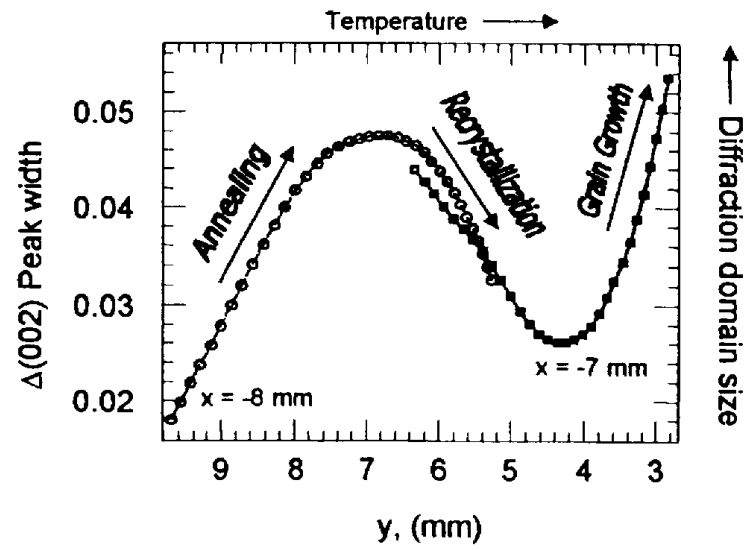


Fig. 13

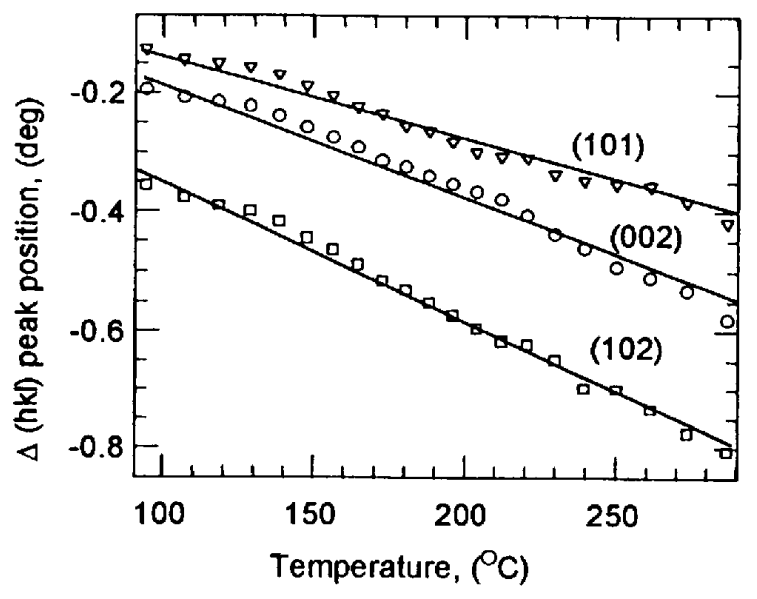

Fig. 14
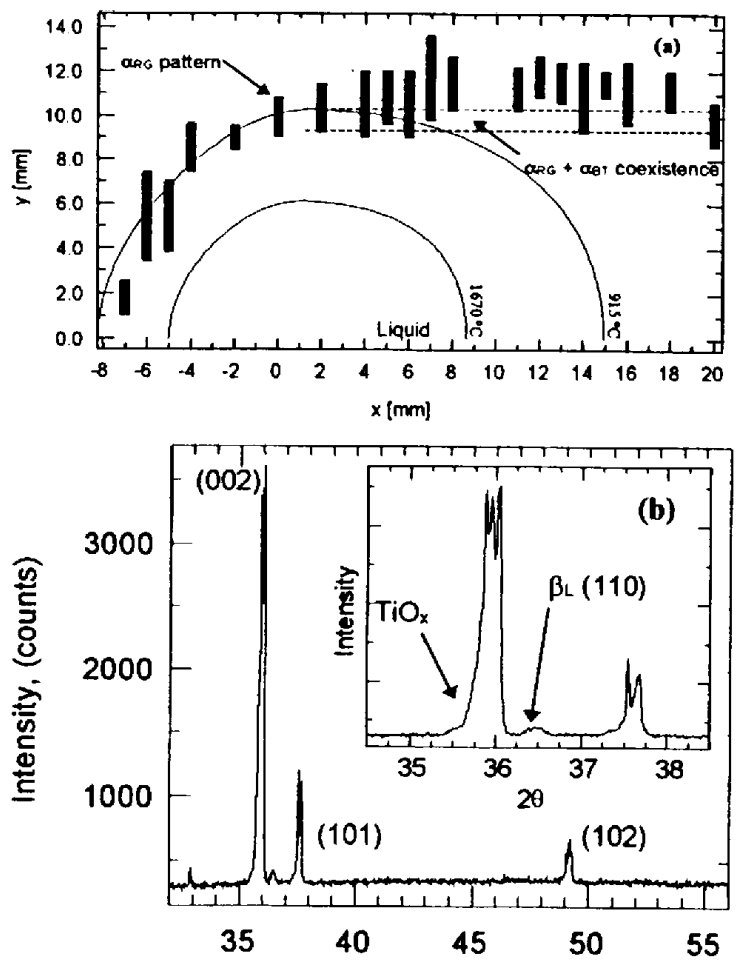

Diffraction angle $2 \theta$, (deg.) 
Fig. 15

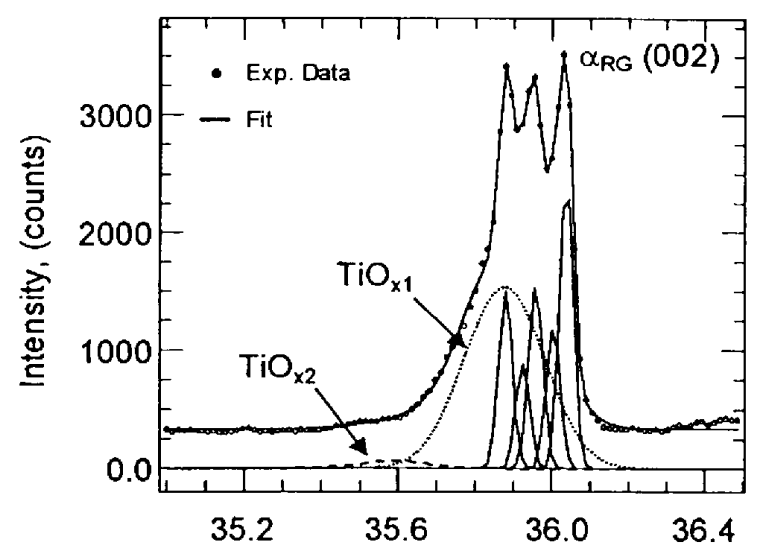

Diffraction angle $2 \theta$, (deg.)

Fig. 16
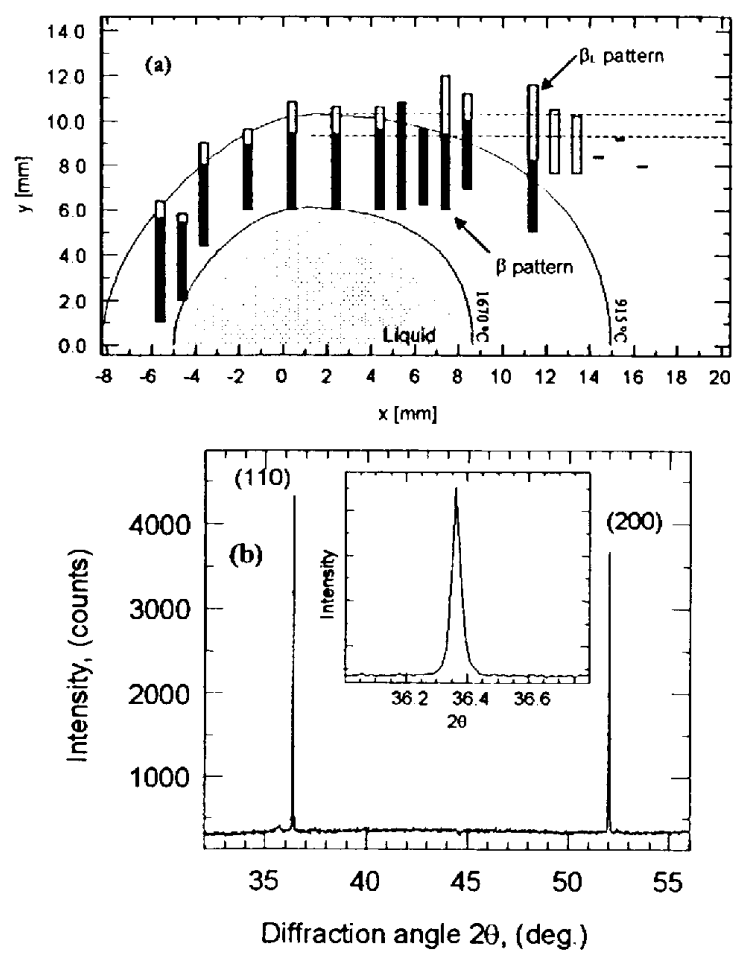
Fig. 17
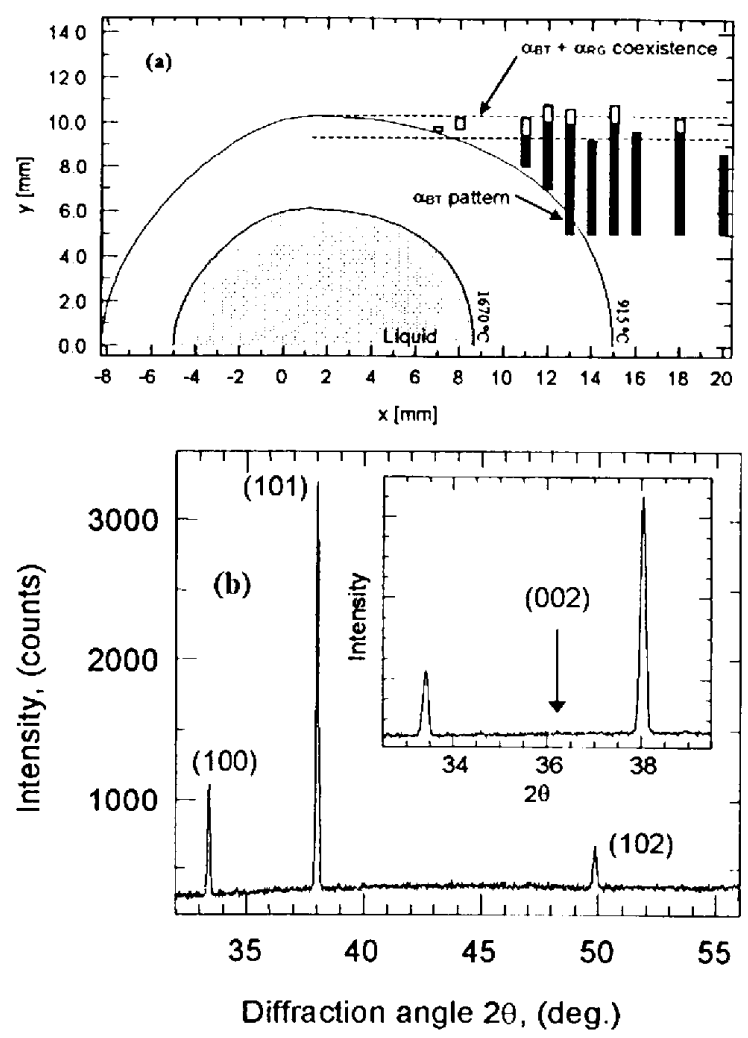

Fig. 18

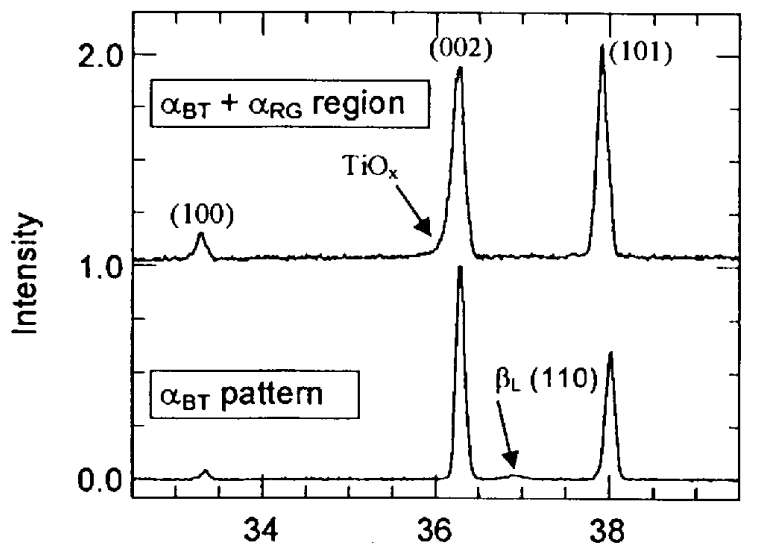

Diffraction angle 2 $\theta$, (deg.) 